\title{
ORIENTAÇÕES DA ARQUITETURA MINOICA E OS CORPOS CELESTES PELA ASTRONOMIA: OBSERVAÇÕES SObre A ConstruÇão Oblíqua XXIII do PALÁCIO de MALIA
}

Marcos Davi Duarte da Cunha ${ }^{1}$

\begin{abstract}
RESUMO: A aplicação de tecnologias como sistemas navegacionais via satélite, softwares de acompanhamento astronômico e imagens de satélite podem auxiliar na análise de edificações minoicas localizadas em Creta. Os dados gerados a partir do emprego dessas ferramentas, as características que as edificações apresentam e os artefatos rituais nelas encontrados sugerem que essas construções tinham uma função de culto associada ao domínio de um saber astronômico. Neste artigo, nós discutimos esses pontos através da apresentação de uma análise inicial da chamada Construção Oblíqua XXIII em Malia.
\end{abstract}

PALAVRAS-CHAVE: Arqueoastronomia; Minoicos; Palácios; Santuários; Medições de tempo.

ABSTRACT: Technologies such as satellite navigational systems, astronomical monitoring softwares, and satellite imagery can be helpful in the analysis of Minoan buildings located in Crete. Data provided by these resources, the characteristic features of these buildings and ritual artifacts found in them suggest a cult function associated with astronomical knowledge. In this article, I discuss these aspects through a preliminar analysis of the Oblique Building XXIII in Malia.

KEYWORDS: Archaeoastronomy; Minoans; Palaces; Sanctuaries; Time measurement.

\section{Introdução}

Nas décadas de 1970/80, a Arqueoastronomia e estudos relacionados, devido especialmente ao sucesso de descobertas importantes como a observação do alinhamento estrutural de santuários com solstícios, equinócios e afins em locais como Stonehenge e outros monumentos megalíticos, inclinaram-se ao esoterismo e misticismo, tendo sua credibilidade como ciência enfraquecida, o que resultou em rejeição desta área por parte da academia. Contudo, com o advento de novos softwares de astronomia, mais precisos e capazes de simulações como cálculos regressivos de tempo e a adição de arqueolinhas na última década

\footnotetext{
${ }_{1}^{1}$ Doutorando em Arqueologia no Museu Nacional da Universidade Federal do Rio de Janeiro (MN/UFRJ) e mestre em História Política pela Universidade do Estado do Rio Janeiro (UERJ), com ênfase em contatos marítimos e rituais de culto da Creta Minoica na Antiguidade Egeia. Atualmente realiza pesquisa sobre o sítio maliota em Creta, mais especificamente sobre a arquitetura e as edificações no Período Palaciano final (1490-1360 a.C.) e suas funções rituais. Também atua como professor colaborador do Núcleo de Estudos da Antiguidade (NEA/UERJ).
} 
do século $\mathrm{XX},{ }^{2}$ a Arqueoastronomia se reestabeleceu e foi reconhecida como conhecimento científico, passando a contribuir com ferramentas importantes para o os estudos arqueológicos. Além do GPS ou GLONASS, 3 que nos fornecem uma posição geográfica precisa, novas ferramentas proporcionaram grande apoio às pesquisas. Softwares gratuitos de imagens de satélite (ex: Google Earth) e de código livre de Astronomia (ex: Stellarium), de manuseio simples e prático, estão disponíveis de forma bastante acessível ao público. Isso permite um uso preliminar de cálculos mesmo em datações distantes de uma área pretendida.

Neste artigo, aplicamos estas tecnologias e fazemos considerações preliminares sobre os alinhamentos arquitetônicos de edificações localizadas no palácio de Malia e proximidades em Creta. Cumpre notar que estamos no preâmbulo de nossas aferições e que, uma vez que feitas as simulações, o estudo culminará na coleta de dados por medições in loco nas respectivas datações de movimentos celestes a fim de obter uma confirmação empírica das datas que são objeto deste estudo. As edificações no complexo arqueológico maliota estudadas estão datadas como Neopalaciano Final (MRII - MRIII), o qual compreende o período entre 1.490 - 1.200 a.C.+/- (Langohr, 2009, p. 74).

\footnotetext{
2 O software Stellarium simula regressão cronológica com precisão de períodos superiores a 2.500 a.C., por exemplo. Arqueolinhas são representações de trajetórias de corpos celestes em cálculos de tempo regressivo que permitem ao observador estabelecer a posição de uma estrela, satélite ou planeta em tempos muito remotos a partir de eventos astronômicos (equinócios, solstícios, helíacos etc.).

3 Sigla para Sistema de Posicionamento Global (em inglês, Global Positioning System). Sigla para Sistema de Navegação Global por Satélite (em russo, ГОНАСС; Глобальная навигационная спутниковая система; Globalnaya navigatsionnaya sputnikovaya sistema).
} 
Tabela 1 - Quadro cronológico

\begin{tabular}{|c|c|c|}
\hline \multicolumn{3}{|c|}{$\begin{array}{l}\text { Sistema Simplificado de Fases Arquitetônicas proposto por J. } \\
\text { McEnroe } 4\end{array}$} \\
\hline Neolítico & Acerâmico & $7000-6000$ a.C. \\
\hline Neolítico & NA5 I & $6000-5000$ a.C. \\
\hline Neolítico & NA II & $5000-4500$ a.C. \\
\hline Neolítico & NM/NR & $4500-4000$ a.C. \\
\hline Neolítico & $\mathrm{NR} / \mathrm{NF}$ & $4000-3000$ a.C. \\
\hline Pré-palaciano Antigo & MA I - MA IIB & $3000-2200$ a.C. \\
\hline Pré-palaciano Tardio & MA III - MM IA & $2200-1900$ a.C. \\
\hline Protopalaciano & MM IB - MM IIB & $1900-1750$ a.C. \\
\hline Neopalaciano & MM III & 1750 - 1700 a.C. \\
\hline Neopalaciano & MR IA & $1700-1580$ a.C. \\
\hline \multicolumn{3}{|c|}{ Erupção em Tera. Período final do século XVII a.C. } \\
\hline Neopalaciano & MR IB & $1580-1490$ a.C. \\
\hline Palaciano Final & $\begin{array}{l}\text { MR II - antigo MR } \\
\text { IIIA2 }\end{array}$ & $1490-1360$ a.C. \\
\hline Pós-palaciano & MR IIIA2 - MR IIIB & $1360-1200$ a.C. \\
\hline Pós-palaciano & MR IIIC & 1200 - 1100 a.C. \\
\hline
\end{tabular}

As características arquitetônicas e seus conjuntos de "parafernálias rituais", 6 sugerem que essas edificações tinham a função de locais de culto. Considerando as localizações espaciais e arrumação arquitetônica, é notável seu alinhamento com movimentações astronômicas de corpos celestes. Tais alinhamentos espaciais do Edifício Oblíquo XXIII apresentam similitudes com os aplicados em alguns santuários de pico importantes, como Anemospilia, Petsophas e Juktas, bem como urbanos, como o Santuário de Gournia e o Santuário de Malia (o qual se encontra fora do complexo palaciano).

\footnotetext{
4 Adotamos as datações propostas por John McEnroe, entre as demais datações existentes, considerando sua forma sucinta e satisfatória ao estudo das arquiteturas e objetos encontrados (McEnroe, 2010: p. 7, Tabela 1.1).

${ }^{5}$ As abreviações de período cronológico se apresentam da seguinte forma: NA - Neolítico Antigo; NM - Neolítico Médio; NR - Neolítico Recente; MA - Minoico Antigo; MM - Minoico Médio; MR - Minoico Recente.

6 A expressão "parafernálias rituais" se refere ao conjunto de artefatos e arrumações arquitetônicas que constituem de um local de culto. (Rutkowski, 1986, p. 11-12).
} 


\section{Metodologia: aplicação operacional}

$\mathrm{O}$ uso dos softwares de astronomia aplicado às estruturas do palácio de Malia consiste em uma coleta de dados cruzados entre os equipamentos de análise astronômica e os de imagens via satélite. O equipamento astronômico tem como função fornecer a imagem do céu no momento que se pretende simular, com afinação de localização de GPS. Assim adquirida, a imagem de satélite fornece a observação espacial da estrutura e sua variante de gradiente em relação ao céu. Tal cruzamento de dados permite um preâmbulo seguro para o empreendimento de uma expedição de coleta in loco, facilitando a observação ao pesquisador.
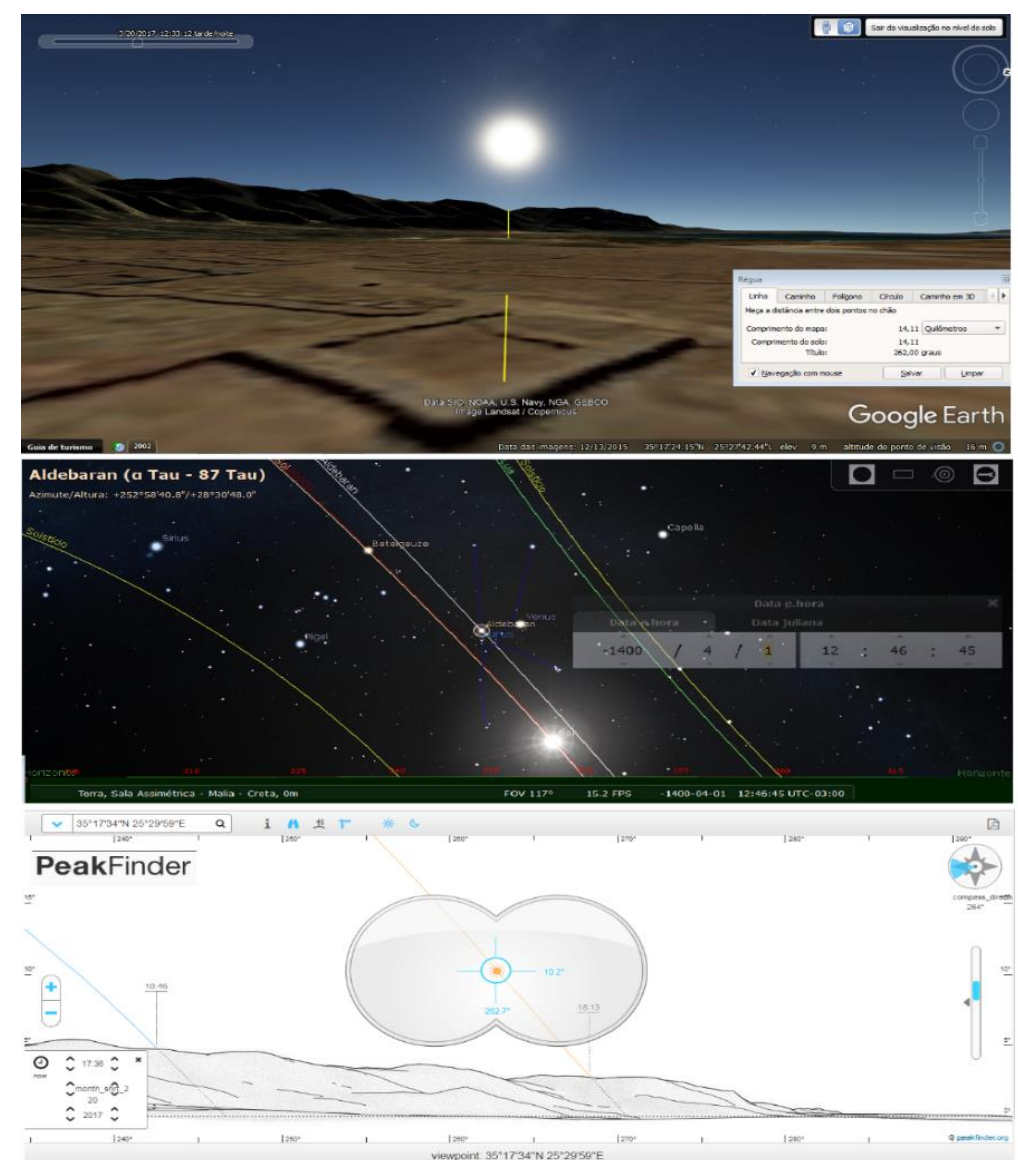

Fig. 1. Simulação 1 - Aplicação combinada de três softwares para averiguação de alinhamento do Edifício Oblíquo de Malia em relação às elevações da região de Mókos, cujo percurso de equinócio de primavera foi em 20 mar. 2017 (Google Earth e PeakFinder) e em 06 de abr. 2000 a.C. (Stellarium) no gradiente $268^{\circ} 08^{\prime} \mathrm{W}$, apresentando alinhamento coincidente. Data de acesso: jan. 2017.

Como podemos observar na simulação combinada, o equipamento de imagem de satélite não permite uma simulação em períodos avançados. Neste caso, acessamos o equipamento astronômico para aferição na data intentada e, 
logo após, a retrocedemos ao período proposto. Todavia, devemos considerar que o percurso solar nos períodos equinociais e solstícios entre essas datas não se alterou e que durante o período de -2000 a.C. o Sol atravessava a constelação de Touro (atualmente ele faz tal percurso em Peixes). Compensadas as devidas faltas, podemos, então, adquirir um cálculo próximo dos episódios celestes apresentados e suas movimentações com a edificação estudada satisfatoriamente. Por fim, podemos também fazer uso de um aplicativo simples criado para auxiliar montanhistas com a orientação espacial do local onde estão trilhando, como o PeakFinder. Assim, podemos simular a posição do indivíduo no local desejado.

Contudo, embora os softwares ofereçam precisão de dados e funcionalidade considerável, a aplicação in loco e o olhar humano do local ainda são essenciais se considerarmos que cada estrutura tem sua peculiaridade de interação com os movimentos dos corpos celestes. Para saber extamente, por exemplo, como a luz solar ou um alinhamento estelar se manifestaria em relação às edificações e suas combinações de esquadros, frestas entre paredes e afins. Esta será a próxima etapa do trabalho. Por ora, esta pesquisa faz uso de três sistemas de navegação astronômica de simples manuseio:

- Stellarium (versão 0.13.3). Software de código livre para acompanhamento astronômico tanto em telescópios quanto em análises de simulação espacial em astrofísica. Foi desenvolvido por pesquisador Fabien Chéreau e sua equipe. $\mathrm{O}$ programa permite fazer cálculos bem aproximados das datas do período estudado, já que o programa corrige variantes de datação tanto pelo Calendário Gregoriano (atual) quanto pelo Juliano. Além disto, ele também corrige o cálculo bissexto dos anos. O software também realiza cálculos de referências antigas através da aplicação de arqueolinhas, as quais oferecem maior precisão nas compilações de registros de observação celeste, como equinócios, solstícios e helíacos em relação ao objeto de estudo material, como edificações, megalíticos, templos etc. Em uma simulação pelo Stellarium podemos, por exemplo, retroceder a uma data que permite ver como o posicionamento desse objeto ficaria em um determinado período, como as variantes de períodos próximos e acima de -2000 a.C. Isto é de suma importância tendo em vista que há uma variação de calibragem dos círculos principais celestes (equatoriais e meridianos) em cerca de $20^{\circ}$ com relação ao nosso período. 
- Google Earth (versão 7.1.7.2606). Programa de orientação geográfica através de fotografias via satélite. Proporciona uma visão do objeto do alto, sua relação com posicionamentos celestes e gradual de inclinação (linha potencial horizontal de um observador local). Sua posição celeste informa as transições das constelações de acordo com o horário de localização do observador, todavia, ela não interfere na análise espacial do local estudado.

- PeakFinder (versão 2.4.6). Aplicativo posicional baseado em dados topográficos para auxílio de montanhistas e afins. Foi desenvolvido pelo programador Fabio Soldati e tem por finalidade fornecer ao observador referências de campo visual com seus acidentes geográficos, através de coordenadas de GPS em conjunção com algoritmos de astronomia, o que proporciona também a observação de percursos solares e lunares. Tal aplicativo permite compreender espacialmente o objeto de estudo, tanto in loco quanto à distância, a partir de como o observador estaria vendo os movimentos dos corpos celestes e seus comportamentos ante a topografia da região.

\section{Os Santuários Minoicos (MRIB-MRII, 1500 a 1360 a.C.)}

Em vários pontos da ilha de Creta existem edificações que contém objetos interpretados como parafernálias de culto. Embora a real função destes locais ainda seja um desafio para os arqueólogos, B. Rutkowski (1986) sugere a classificação dessas edificações como lugares de culto. Dentre as principais construções principais destacamos:

- Santuários de pico (MAIII-MMIA), localizados em posições topográficas elevadas, muitas vezes próximas de picos proeminentes como Monte Jouktas e Petsophas. Os santuários de pico aparecem em lugares próximos aos dos palácios, segundo A. Peatfield (1987, p. 89-93). Para J. McEnroe (2010, p. 33), tais locais de culto estariam ligados aos palácios a fim de garantir a manutenção do poder por meio da associação com o universo religioso. O emergir de novos centros urbanos em posições elevadas e a visão privilegiada que elas ofereciam sugerem uma presença palaciana de domínio político e territorial em locais distantes. Exemplos disto são os santuários de Anemospilia, Profiti Elias, dentre outros. 
- Templos e santuários públicos ou urbanos, domésticos e palacianos (MRIIMRIII) caracterizam-se pela localização dentro ou nos arredores dos palácios (Rutkowski, 1986, p. 10-17). De acordo com J. McEnroe (2010, p. 66-67), a existência de artefatos de culto e ritual são importantes para um apontamento sobre a utilização dessas estruturas, embora ainda haja dúvidas sobre muitos locais. Na mesma linha, Poursat (1966, p. 514-551) considera que a escassez deste modelo de edificação na ilha, excetuando o Santuário de Malia, é um fator complicador para o entendimento destes edifícios.

Exemplos dessa arquitetura do Palaciano Final (MRII-MRIII) emergem na cultura minoica e podem ser detectadas em alguns sítios arqueológicos. B. Rutkowski classifica cerca de cinquenta exemplares na ilha de Creta (Rutkowski, 1986, p. 12), dos quais podemos citar quatro como exemplos: o Santuário Público de Gournia,7 uma cidade minoica que teve seu período funcional de 2.200 a.C. até seu total abandono em 1.200 a.C. (Hood, 1973, p. 162-165); a Construção Oblíqua XXIII (Chapoutier, 1936) na Ala Norte do palácio de Malia; o Santuário de Malia, descoberto em 1965 nas proximidades do palácio (Poursat 1966, p. 514); e o edifício denominado Santuário dos Chifres em Malia, escavado em 1956, cuja datação foi no MRII (McEnroe, 2010, p. 65-66).

De acordo com J. McEnroe (2010, p. 117-132), estas edificações surgiram na ilha em um momento de perceptível diminuição da permanência cotidiana humana ou até mesmo quando do abandono das dependências dos palácios e/ou reocupações. Possivelmente, essa movimentação foi ocasionada por uma grave crise institucional somada a diversos fatores. Para S. Hood (1973, p. 58-60), o enfraquecimento das realezas minoicas pode ter sido resultado de grandes migrações do continente europeu, o que teria ocasionado um aumento populacional e, consequentemente, sérios problemas para a ilha de Creta, como um desequilíbrio de abastecimento e distribuição de insumos pela administração palaciana. Todavia, atualmente, esta teoria é criticada severamente pela pouca evidenciação. H. Effenterre (1986, p. 100-103) afirma que as catástrofes teriam sido ocasionadas pela erupção de um vulcão em Tera (MRIA-MRIB), o que teria promovido severos danos às estruturas da marinharia minoica. Abalos sísmicos de grande abrangência e o alcance das ondas do mar (tsunamis) após a explosão

\footnotetext{
7 A adoção do termo proposto por McEnroe em detrimento de outros, embora também não seja suficientemente satisfatória, advém da necessidade de uso e facilidade ao desenvolvimento do estudo, além de ser de um estudo mais recentes.
} 
teriam provocado destruições consideráveis na ilha, atingindo também seus palácios que, posteriormente, foram reconstruídos, porém, o efeito colateral da catástrofe permaneceria a longo prazo.

Nesse ínterim, ritualísticas religiosas dentro do contexto minoico emergiriam fora dos palácios, surgindo nas cidades edificações peculiares que contribuiriam para uma espécie de popularização ou descentralização de um "saber ritual" útil tanto para efeitos religiosos como também para preceitos político-estratégicos, como a capacidade de definir estações do ano, por exemplo (Dickinson, 2006, p. 233-250). Para Ellen Adams (2004, p. 30), embora haja uma grande lacuna em se discernir o que é ritual social e ritual religioso, é considerável o papel dos locais de culto como celebrantes de um elemento de identidade de grupo além da prática religiosa. A marcação do tempo como ferramenta de poder pode ser uma dessas identidades.

Entretanto, sobressai nas estruturas das edificações do complexo maliota diversas marcações em forma de símbolos na alvenaria que compõem a arquitetura local, como pedras de soleiras de porta, esquinas de passagens, corredores de acessos, colunas e paredes. Tais marcações, inicialmente consideradas como "marcações de pedreiro" podem estar ligadas a elementos de cunho astronômico, como veremos a seguir.

\section{Marcações e símbolos na alvenaria palaciana}

De acordo com a pesquisadora N. Marinatos (2010, p. 104-113), os símbolos do labrÿs ${ }^{*}$ ("machado duplo") e os chifres cerimoniais $\downarrow$ têm como imagética representativa a celebração do Sol como pessoa divina e a seu percurso celeste em determinado período, alinhado com a montanha $M$ em uma representação dramática da cosmogonia minoica. 

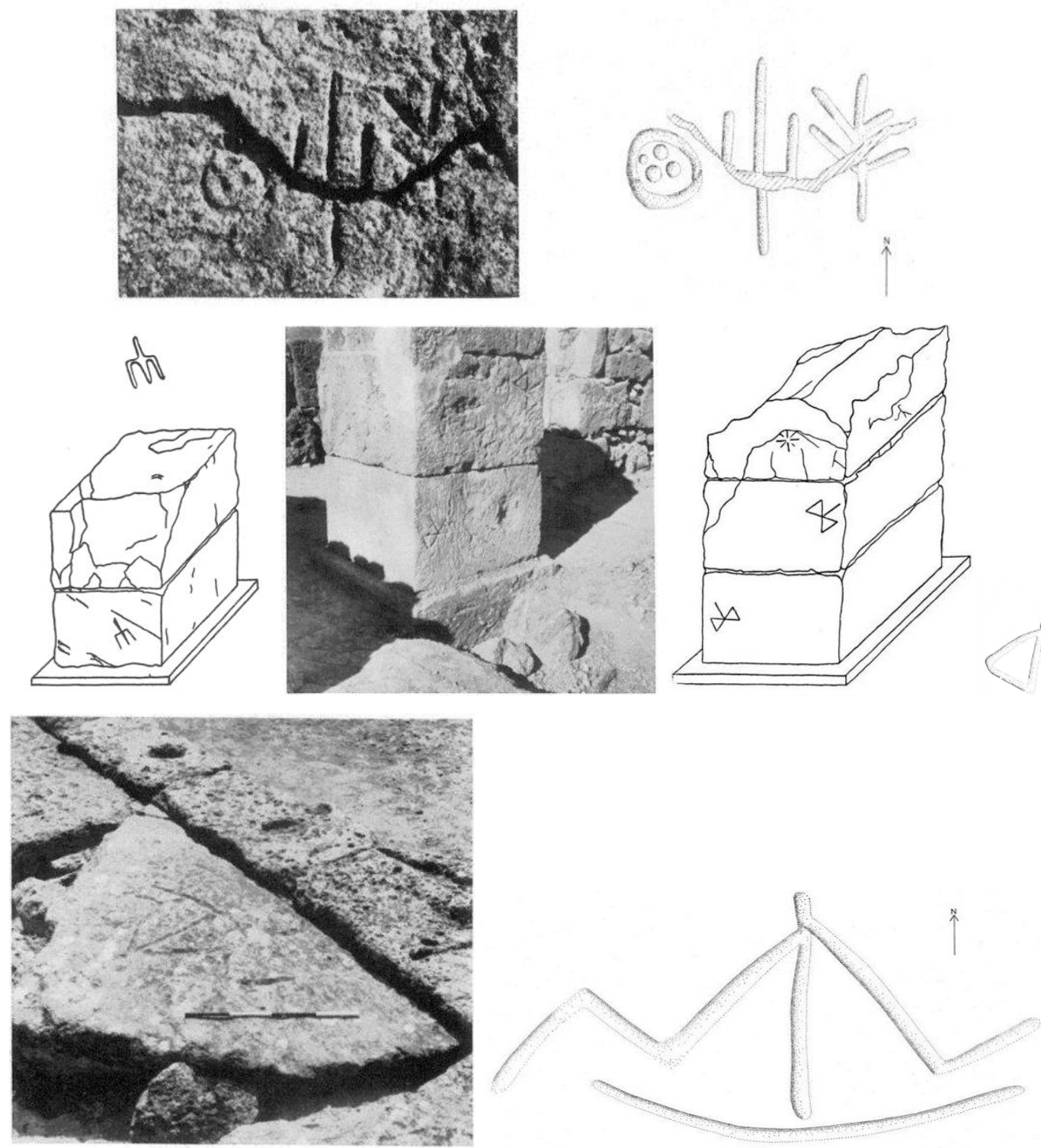

Fig. 2. Exemplos de signos registrados na alvenaria de Malia (Pelon, 1980, p. 98-99, 191, 195)

As pesquisas de Marinatos (2010, p. 104-110) também realizam comparações que demonstram a existência de padrões semelhantes em outras culturas, como no caso da cultura egípcia, que apresenta um símbolo solar entre montanhas. Neste caso, as figuras votivas como as GWUA $^{8}$ (vide fig. 3d) apresentam uma expressividade interessante quando observamos suas verossimilhanças com símbolos encontrados na religião minoica, o que sugere, na forma expressiva corporal, uma mesma representação simbólica dos chifres cerimoniais e machado duplo. Estes símbolos grifados em diversas partes dos palácios podem ter ligação com alinhamentos de corpos celestes.

${ }^{8}$ GWUA é a abreviação convencional em inglês para imagens votivas femininas que apresentam os braços levantados (Goddess With the Upraised Arms). 


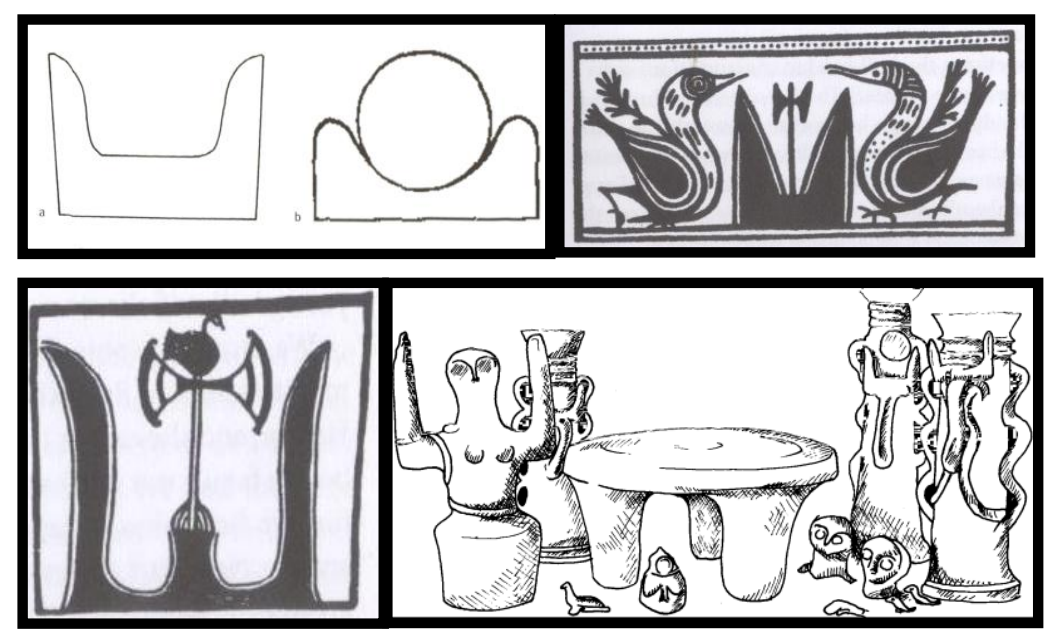

Fig. 3. a) Desenhos demonstrando caracteres minoicos e egípcios com grande solar, ideograma egípcio para "montanha"; b, c) detalhes de um esquife encontrado em Giofyakia e em uma pintura de um vaso de argila (Marinatos, 2010, p. 107); d) Artefatos rituais encontrados no Santuário Público de Gournia (Marinatos, 1993, p. 223).

Certamente para a ilha essa consciência de tempo era algo visceralmente importante para administrar o sistema de rotas marítimas de comércio exterior dos palácios e seus congregados (Lambrou-Phillipson, 1991, p. 12-15). Por exemplo, o momento equinocial é de grande importância para as marcações necessárias de tempo assim como os solstícios e helíacos nas demarcações estacionais. Cerimônias como as tauromaquias, por exemplo, poderiam ter suas celebrações durante a passagem do Sol pela constelação Taurus ${ }^{9}$ no período equinocial periódico, anunciando a chegada da primavera no hemisfério norte e, consequentemente, a época da colheita, assim identificado em diversos povos também. Esse período também assinalava o início da temporada de navegação, quando os ventos e as condições marítimas e climáticas eram mais favoráveis.

Recentemente, pesquisas e medições locais por Mary Blomberg e Göran Henriksson (2013, p.60-64 e p. 96-114) apresentaram importantes descobertas referentes às orientações espaciais de edificações minoicas no palácio de Cnossos, Monte Juktas e Petsophas. Com a observação exata do tempo e local, pôde-se constatar que no corredor da Casa do Escriba em Cnossos o movimento de sombras e luzes, durante o período equinocial, atingia uma determinada posição que apresentava alinhamento com as marcações de machados duplos. A luz

9 O eixo da Terra oscila, perfazendo, em um espaço de 26.000 anos, um círculo completo. Isto influencia na transição do Sol e constelações, pois de tempos em tempos o Sol atravessa de uma constelação para outra durante os eventos equinociais. Neste caso, o período estudado encontrase na passagem do Sol em Touro (4.300 a 2.100 a.C.). 
atingia no final do corredor uma pedra côncava abastecida de água, resultando em um reflexo na parede em outra marcação num período exato no ano (vide fig. 4).

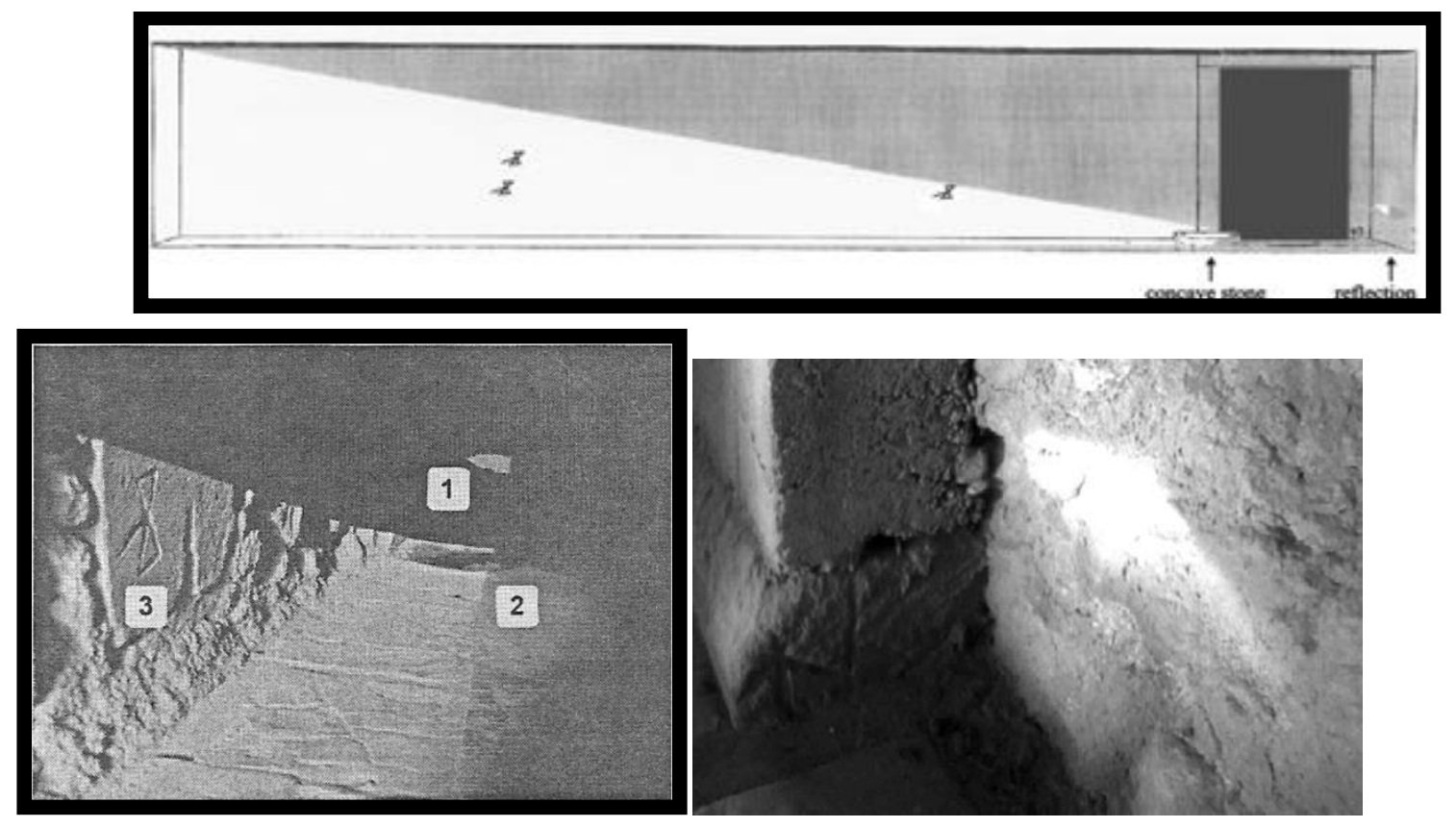

Fig. 4. Experimento de marcação equinocial com base na edificação "Corredor da Casa do Escriba”, em Cnossos. A gravura demonstra a linha de sombra e seu percurso até à pedra ao umbral da porta, onde se refletia a luz na parede. Vemos na primeira foto a luz acima da marcação do signo labrüs (3), a pedra côncava refletiva (2) e, por fim, o reflexo na parede na foto 2. (Henriksson, 2013, p. 62)

As constelações e astros celestes são observados e utilizados como ferramentas de orientação do homem desde eras remotas. Por exemplo, estrelas navegacionais como Aldebaran (denominação astronômica MUL.MUL) já eram funcionais na Mesopotâmia em cerca de 5.000 a.C. (Mourão, 1995, p. 813). Junto com esta constelação, os babilônios também já apresentavam registros sobre as observações das Plêiades (aglomerado estelar das "sete irmãs") para marcações calendáricas e afins (Verderame, 2015, p. 109-117).10 De acordo com MacGillivray (2000, p. 53-55), as Plêiades e as Híades formam junto com Aldebaran e outras estrelas a constelação de Touro, cujo papel visceral vigora na orientação da temporada das navegações.

\footnotetext{
${ }^{10}$ Hesíodo em sua obra Os Trabalhos e Dias adverte sobre as temporadas de navegação de acordo com a observação dos períodos das Plêiades e seus percursos no céu. Embora Hesíodo seja uma fonte posterior em relação ao nosso estudo (700 a.C aproximadamente), devemos considerar que praticamente a navegação na região em nada se modificou neste espaço de tempo desde os minoicos.
} 
Uma consideração importante referente ao aglomerado das Plêiades é que seu percurso celeste por volta do II Milênio a.C. concorreu com o percurso equinocial, tendo em vista que o gradiente de seu ocaso se encontra entre $275^{\circ} \mathrm{W}$ (atualmente o aglomerado encontra-se em $300^{\circ} \mathrm{W}$ ), posição que se alinha às entradas das estruturas de santuários aqui apresentadas. De acordo com a pesquisadora A. Sparavigna (2008, p. 2), os povos antigos desse período (no caso de seu estudo, celtas, egípcios, gregos e sioux) utilizavam esse aglomerado para orientações de tempo, como a marcação dos períodos da agricultura e também a celebração dos mortos. As Plêiades despontam no horizonte a oeste durante outubro e novembro, tempo de encerramento das navegações, preparação para as estações mais frias e, nas regiões do Mediterrâneo, é o tempo propício para aragem e semeadura da terra (vide imagens 13 e 14 em anexo).

Outro aspecto a ser levado em consideração no contexto estudado com relação às linhas do céu, é considerar os períodos de passagens equinociais do Sol entre as constelações. Em nosso caso, podemos afirmar que, praticamente na duração da civilização minoica, o equinócio de primavera no hemisfério norte (o marcador de tempo visceral para a navegação) se faz pela travessia em Touro, o que sugere que este período de travessia era caracterizado por festividades como as tauromaquias minoicas. ${ }^{11}$

Uma das práticas de observação de tempo celeste identificada nos assentamentos minoicos está justamente nas suas estruturas arquitetônicas como ferramentas de medição, ou seja, suas construções junto com o posicionamento da luz solar em determinados períodos definiria seus calendários. No alinhamento da fachada desses santuários vigora a posição de gradiente oscilante em $265,3^{\circ}$ para $310^{\circ}$, ou seja, seus posicionamentos alinhamse com as travessias equinociais e de solstícios leste-oeste-leste (vide simulações anexas).

\section{O Edifício Oblíquo XXIII de Malia}

\footnotetext{
${ }^{11}$ As tauromaquias ou taurocatapsias minoicas consistiam, pelo o que sugerem afrescos, sinetes etc., em um salto sobre o dorso do touro pelo acrobata ou a submissão do animal retendo-o pelos chifres. Embora não hajam evidências consistentes sobre se essas celebrações eram ligadas com a travessia do Sol pela constelação de Touro no período equinocial de primavera, que oscila nos idos de abril próximo do II milênio a.C., rituais de passagem de tempo eram comuns em outros grupos humanos da região do Mediterrâneo. Cf. Linacero, 2007, p. 197-223 e Cunha, 2013, p. 4250.
} 
Localizado no lado Norte da ilha a poucos quilômetros de Cnossos e um dos mais próximos do mar e seu porto, com medidas de cerca de $7.500 \mathrm{~m}^{2}$ de área construída, Malia emerge das escavações como um dos maiores palácios da ilha, abaixo apenas de Cnossos com $13.000 \mathrm{~m}^{2}$ e Festos com $8400 \mathrm{~m}^{2}$. Suas edificações possuem diversas etapas e períodos que variam entre 2000 a.C. a 1370 a.C. que por vezes se misturam de tal forma que tornam hercúleo o desafio dos pesquisadores em datar exatamente certas dependências do palácio com maior precisão ou mesmo em estabelecer um consenso sobre as datações (Langohr, 2009, p. 74).

O palácio de Malia foi descoberto por Joseph Hazzidakis, Éforo Honorário de Antiguidades de Creta, em 1915. As primeiras escavações promovidas pela Escola Francesa de Atenas aconteceram em três momentos pelos pesquisadores Louis Renaudin e Jean Charbonneaux (1922-1923), Jean Charbonneaux e Ferdinand Chapoutier (1924) e Fernand Chapoutier e René Joly (1925-1926).

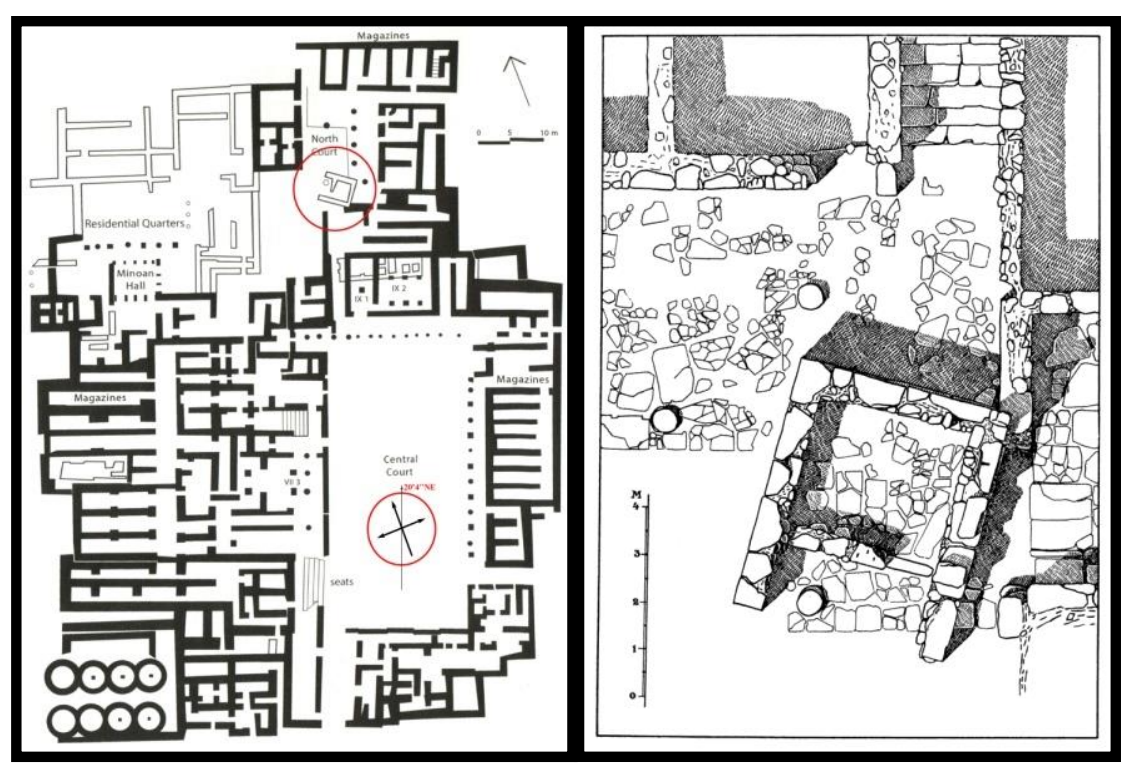

Fig. 5. Plantas 1 e 2 - Palácio de Malia e suas dependências evidenciadas pelas escavações (Shaw, 2015, p.7). As marcações de posição geográfica nos permitem uma observação de como se fazia o percurso celestial. Acima assinalada encontra-se o "edifício oblíquo" ao lado representado em croqui por Fernand Chapoutier na segunda escavação de 1925/26. Nota-se o esquadrinhamento em discordância ao assoalho de construção anterior (Chapoutier, 1936, p. 60).

Ao passo que as escavações evidenciavam as estruturas, notou-se que o palácio de Malia apresenta alinhamento de suas dependências por base inicial da área denominada Corte Central onde se localiza o pátio principal. Tal área possui 
uma orientação cardeal de norte inclinado, ou seja, o alinhamento do terreno tem seu norte geográfico apontando na junção de fundo (planta 1). Isto permite que o percurso celeste manifeste movimento em diagonal em suas salas, o que possivelmente facilitaria a observação e marcação de períodos através da visualização de constelações e astros.

Contudo, alguns metros à frente da Corte Central, na parte denominada de Corte Norte, uma dependência evidenciada durante a segunda etapa de escavações (1924), em relação às demais edificações erguidas em diversos períodos se encontra visivelmente desalinhada (planta 2). Foi denominada pelos pesquisadores como "edifício oblíquo XXIII" (Bâtiment Oblique). Considerado de uma potencialidade funcional específica com base em observações do céu e também em virtude de seu posicionamento, tal edificação pode nos oferecer informações referentes às observações celestes palacianas entre as demais salas do local.

Segundo Ferdinand Chapoutier (1936, p. 19-20), o Edifício Oblíquo se insere na paisagem arquitetônica da Corte Norte do palácio como um "obstáculo" entre as dependências da ala Norte com a Corte Central. Chapoutier descreve o Edifício Oblíquo como uma peça fina de acabamento e construção considerável. Todavia, considerando a divisão de camadas, entende que a construção é de período posterior, porém, não de um período onde as demais dependências palacianas achavam-se abandonadas. O esmero com a edificação tem seus detalhes apontados pelo pesquisador, como o preenchimento da argamassa de ammouda $^{12}$ utilizada com inserções de ramos em seus revestimentos e a adição de uma soleira de sideropetra ${ }^{13}$ em sua única entrada. Na escavação do Edifício Oblíquo praticamente nada foi encontrado que sustente quaisquer suposições da referente sala no que concebe de seus ofícios originais. Chapoutier (1936, p. 47) cita a descoberta de uma figura votiva em terracota no vestíbulo do edifício (figura 6). Todavia, o pesquisador adverte que a presença desse artefato não seria evidência suficiente para considerar o local como um santuário.

Contudo, Chapoutier não se aprofunda sobre as funções do Edifício Oblíquo, relatando-o apenas em suas dimensões e constituições materiais como de praxe. Conclui também que tal edificação merecia atenção maior de pesquisas

\footnotetext{
12 Espécie de rocha muito usual em Malia. Geralmente possui três composições: calcário conchífero, calcário compacto, organo-dentrítico e arenito dunário. Cf. (Allegrette, 1997: p. 2).

${ }_{13}$ Calcário-azulado de muita predominância na região de Creta próxima de Malia. Cf. (Effenterre, 1980: p. 100-105).
} 
que contribuíssem numa aproximação de sua função a de um local dedicado às divindades.

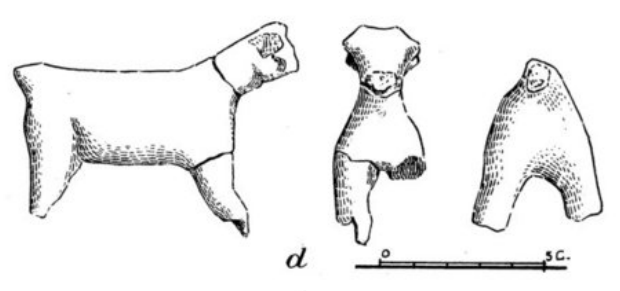

Fig. 6. Figura taurina de terracota encontrada no vestíbulo do Edifício Oblíquo de Malia (Chapoutier, 1936, p. 43)

No decurso das explorações arqueológicas locais do palácio de Malia, Olivier Pelon (1980, p.18) considerou que a área da Corte Norte seria a parte mais antiga do complexo palaciano. Todavia, ao citar o Edifício Oblíquo, ele apontou uma interrupção na edificação com alguma função interligada ao prédio total do quarteirão XXI. Em suas descrições ao Edifício Oblíquo, O. Pelon detalha também sua posição "assimétrica" em referência ao assoalho da construção consideradamente anterior ao XXIII (1980, p. 78).

Assim, o Edifício Oblíquo suscita questionamentos justamente por sua posição estar fora de alinhamento com as demais construções do complexo. Se por um lado, podemos considerar que esta edificação foi posterior, fora das épocas de auge do convívio palaciano, por outro, não devemos ignorar que seu manejo posicional esteja propositalmente arquitetado desde de sua construção. O esquadrinhamento da edificação pode nos oferecer indícios de suas funções intencionadas.

O desalinhamento do Edifício Oblíquo apresentado pelos pesquisadores em perspectiva "obstrutiva" das dependências do palácio, pode ser interpretado, a princípio, de forma intencional se o considerarmos em relação à fachada e seu campo direcional, pois as estruturas da própria edificação estão em comum alinhamento, sugerindo uma função determinada da sala em relação a alguma influência externa. Se considerarmos em hipótese sua descrição posicional geográfica, a entrada está voltada para cerca de $310^{\circ} \mathrm{NW}$ com campo de abrangência visual de sua entrada em torno de $278^{\circ} \mathrm{W}$ a $315^{\circ} \mathrm{N}$. Nesta posição, com base em cálculos de observação astronômica e com as devidas correções de 
tempo ${ }^{14}$, é possível ter uma perspectiva da visibilidade de movimentos celestes, como a constelação de Touro e a travessia do Sol através de seus chifres, delimitando, assim, as marcações de calendário equinocial no palácio.

Em suma, os primeiros escavadores consideraram que o Edifício Oblíquo de Malia seria um "possível santuário” de construção posterior, tendo em vista sua posição destoante da organização palaciana geral. Todavia, praticamente nada se encontrou de evidências que reforcem materialmente a sugestão até hoje considerada. Porém, Olivier Pelon (2005, p. 195), em pesquisas posteriores, sugeriu que a construção poderia ser um possível local de culto construído posteriormente à época em que o palácio funcionava como tal.

Os dois exemplos de santuários abaixo indicam alinhamentos das estruturas arquitetônicas que nos sugerem essa utilização para fins de observações do céu dos santuários. Isso corrobora com nosso estudo e a hipótese astronômica apresentada ao Edifício Oblíquo.

\section{O Santuário de Malia do MMII}

Localizado a cerca de 300 metros do palácio e à leste, este santuário emergiu ao conhecimento através das escavações realizadas em 1965, quando se constatou as peculiaridades que indicam a possibilidade de local de culto.

De acordo com J. Poursat (1966, p. 518) a construção possui composição esmerada, com recintos elaborados com lajes em sideropetra e lacunas de parede cuidadosamente preenchidas com pequenos seixos e estuque. Constatou-se também a presença da ammouda como material de acabamento. Umas das observações interessantes (e úteis ao nosso estudo) está na denominada Rua Norte, que abrange todo o edifício com um amurado de doze metros de comprimento. Esta parte suscita no pesquisador o questionamento sobre sua utilidade, tendo em consideração que esta rua, assim denominada, não vai a lugar nenhum ou mesmo se conecta com a edificação do santuário (Poursat, 1966, p. 527). Para Poursat, o que pode ser interpretado como uma rua encontra-se alinhado com uma marcação celeste do solstício de inverno (vide simulação no anexo de imagens).

\footnotetext{
14 Existe uma variante de alinhamento ao observador em referência aos corpos celestes a cada período determinado por seus próprios percursos em relação ao planeta Terra, assim como também há uma variante nos polos de norte magnético.
} 

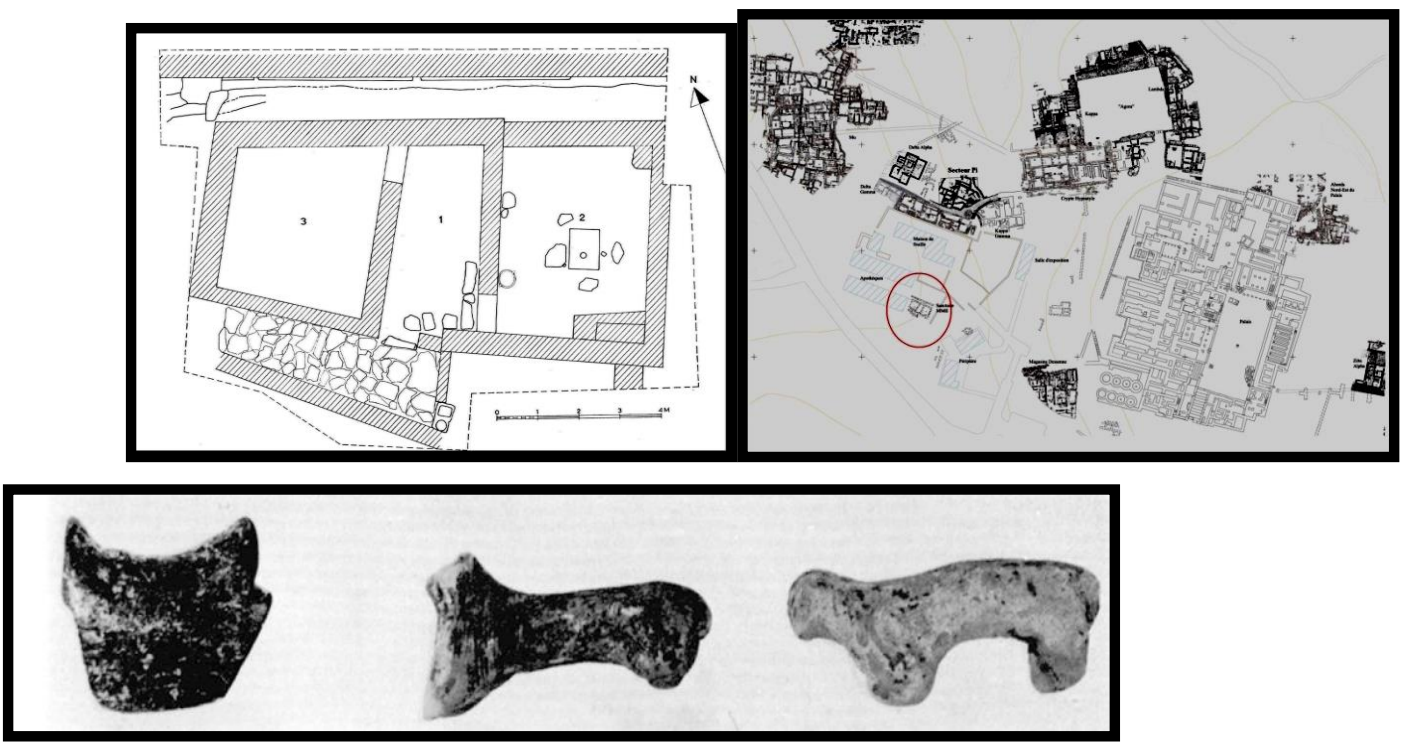

Fig. 7. Santuário de Malia do MMII por Poursat 1966. Nota-se a posição do muro denominado de Rua Norte em paralelo com a edificação acima. Ao lado, planta topográfica com o local do santuário assinalado (Fadin, 2004). Abaixo: figuras taurinas em terracota encontradas entre as demais evidências nas escavações do santuário (Poursat, 1966: fig.26)

Observando suas dimensões, podemos notar que a entrada do santuário possui um esquadrinhamento próprio da construção onde percebemos que a parte externa da parede estreita a entrada da edificação, ocasionando assim um alinhamento com um gradiente que coincide com as medições dos Equinócios de Primavera e Outono.

\section{Santuário de Gournia}

Dos exemplos que adotamos ao estudo, o santuário público da Vila de Gournia se encontra dentro deste complexo arqueológico com uma via de acesso direta à sua entrada, possivelmente usual para procissões e afins (McEnroe, 2010, p. 111-113). Descoberto durante expedições empreendidas entre 1901 e 1904 pela pesquisadora Harriet Boyd-Hawes e equipe (Pottier, 1910, p. 19-20), a edificação figura cronologicamente entre exemplos datados do final do MMII, como o santuário de Malia citado anteriormente, o qual O. Dickinson (2008, p. 264-286) denomina como um santuário público. 

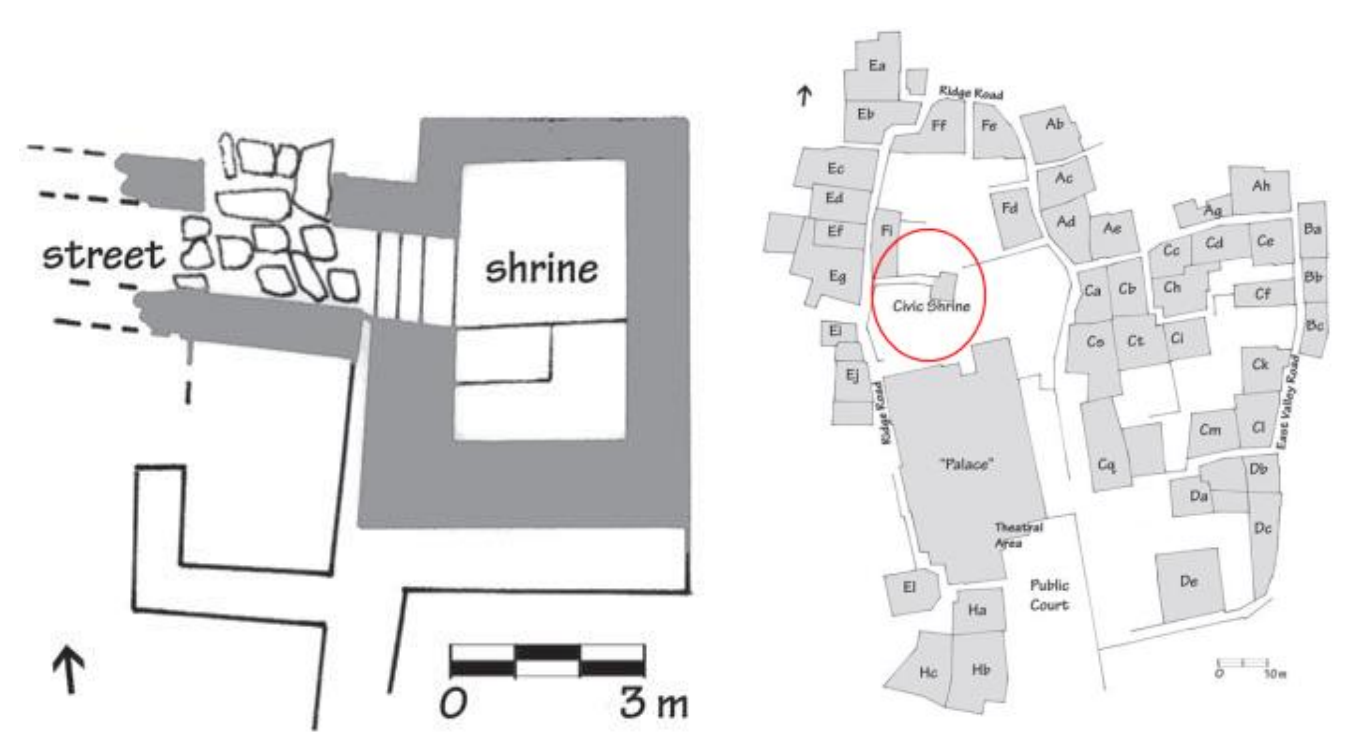

Fig. 8. Planta de um santuário público em Gournia do MM II (detalhe) por Hawes (1908, p. 64). No croqui é possível notar o alinhamento da porta com o gradiente posicional $270^{\circ}+/-$ do alinhamento equinocial. A segunda figura é a planta da Vila de Gournia por McEnroe (2010, p. 104) com o santuário assinalado.

As principais peculiaridades observadas pelos escavadores nestes santuários dizem respeito tanto aos achados arqueológicos que evidenciam suas funções, quanto aos aspectos estruturais arquitetônicos, de certo modo simplórios, quando levamos em conta comparações com outras arquiteturas religiosas da ilha. A entrada do santuário público de Gournia está situada a $267,82^{\circ} \mathrm{W}$, tal como a rua que culmina no santuário. Isto permite uma observação de movimentos celestes como o equinócio, por exemplo. Tal alinhamento se posiciona de maneira excepcionalmente interessante em relação às montanhas do local (vide anexo de imagens). Esta manifestação de marcação com a montanha também se apresenta em outros santuários observados deste período e aqui citados.

\section{Conclusão}

O domínio de tecnologias para a marcação de estações do ano através das observações celestes e os movimentos de seus corpos é perceptível na sociedade minoica e na constituição de seus palácios e templos. Tal domínio concedia à realeza palaciana minoica tanto o poder de regular o tempo e as datas para seus rituais e celebrações, como também o domínio das rotas de navegação. Ao aplicarmos softwares de astronomia e observação espacial nas evidências arqueológicas, podemos constatar que os palácios, seus templos e locais de culto eram por si próprios instrumentos de medição dos movimentos de corpos 
celestes. Assim, podemos concluir que o domínio de um saber astronômico era de suma importância para os habitantes do palácio e que ele estava intimamente ligado às questões religiosas e rituais, bem como marítimas, estando evidenciadas, como vimos, nas entranhas de suas próprias edificações.

\section{ANEXO DE IMAGENS DE APLICAÇÃO ASTRONÔMICA}

Para fins de apresentação de projeto, selecionamos algumas imagens captadas dos softwares utilizados na pesquisa. Nelas, podemos observar a comparação de alinhamentos dos santuários de picos e urbanos e suas respectivas linhas de horizonte em alguns fenômenos naturais celestes utilizados para orientação na Antiguidade. Alguns cuidados na coleta e cruzamento de dados entre equipamentos devem ser considerados, como por exemplo, o uso do Google Earth. Ele não nos permite uma simulação de data muito avançada. Neste caso, deve-se compensar um erro de cerca de $20-15^{\circ}$ equatoriano a fim de observar a mesma simulação no período desejado (cerca de -200o a.C.). Para uma finalização de cálculo mais preciso utilizamos juntamente o software Stellarium e sua função de Arqueolinhas. As simulações apresentadas no anexo são exemplos de como a tecnologia nos auxilia numa introdução preliminar aos objetos arquitetônicos em questão. Foram colhidas imagens de simulação de alguns santuários da ilha para efeito de comparação de seus alinhamentos com as montanhas.

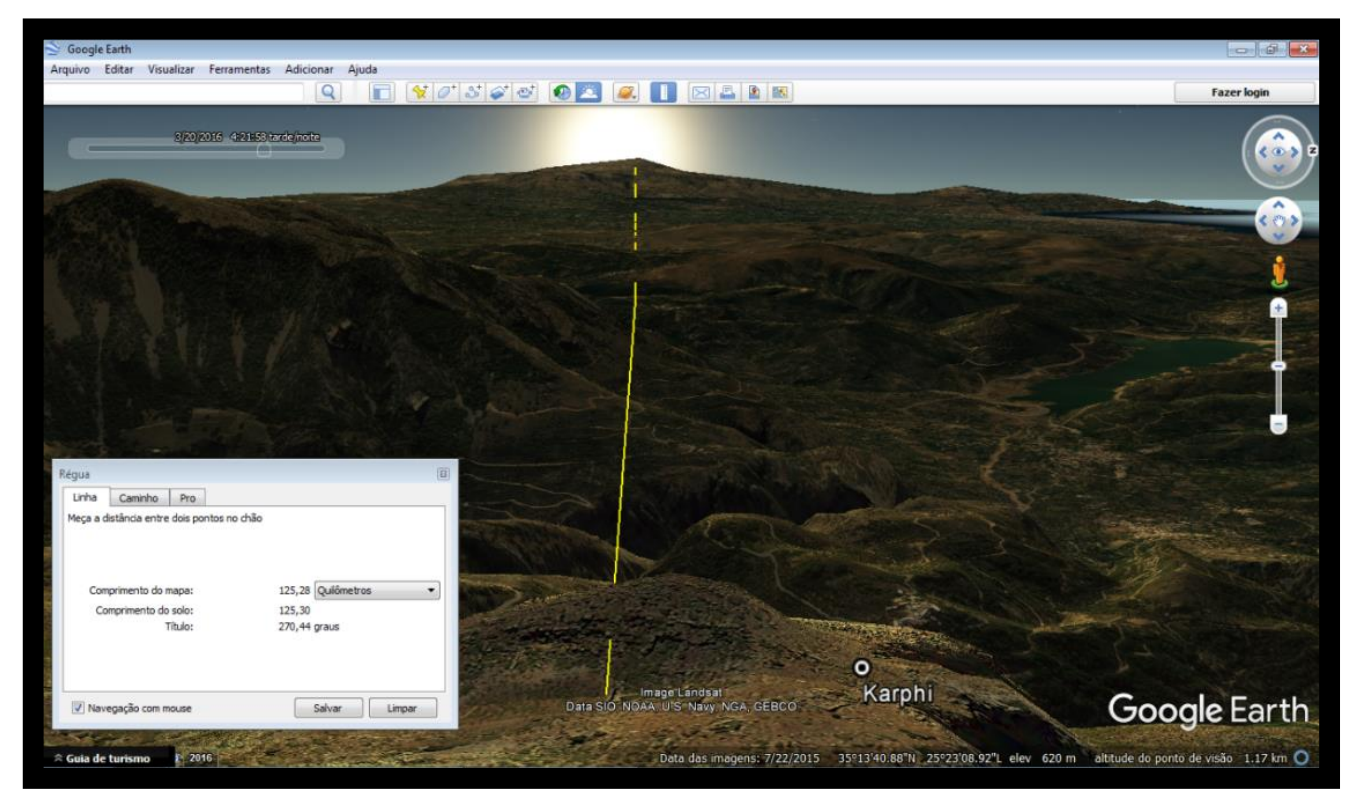

Fig. 9. Simulação 2 - Alinhamento de estrutura do santuário de Karphi em relação à montanha no percurso de equinócio de primavera de 20 de março de 2016. Gradiente $270^{\circ} 44^{\prime}$ W. Data de acesso: nov. 2016. Software: Google Earth (versão 7.1.7.2606) 


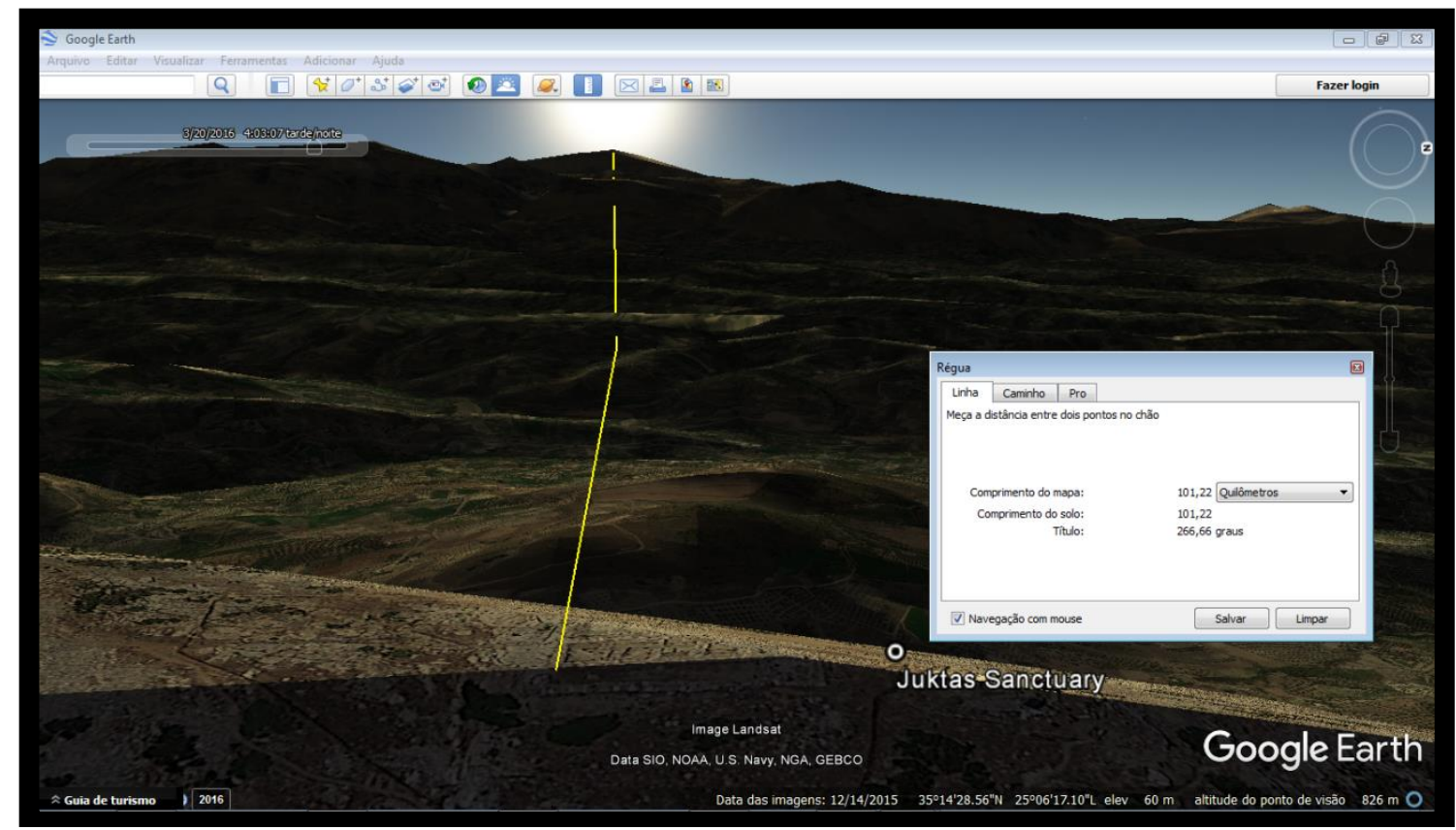

Fig. 10. Simulação 3 - Alinhamento de estrutura do santuário do Monte Juktas em relação à montanha no percurso de equinócio de primavera de 20 de março de 2016. Gradiente 266 $66^{\circ} 6^{\prime}$ W. Data de acesso: nov. 2016. Software: Google Earth (versão 7.1.7.2606)

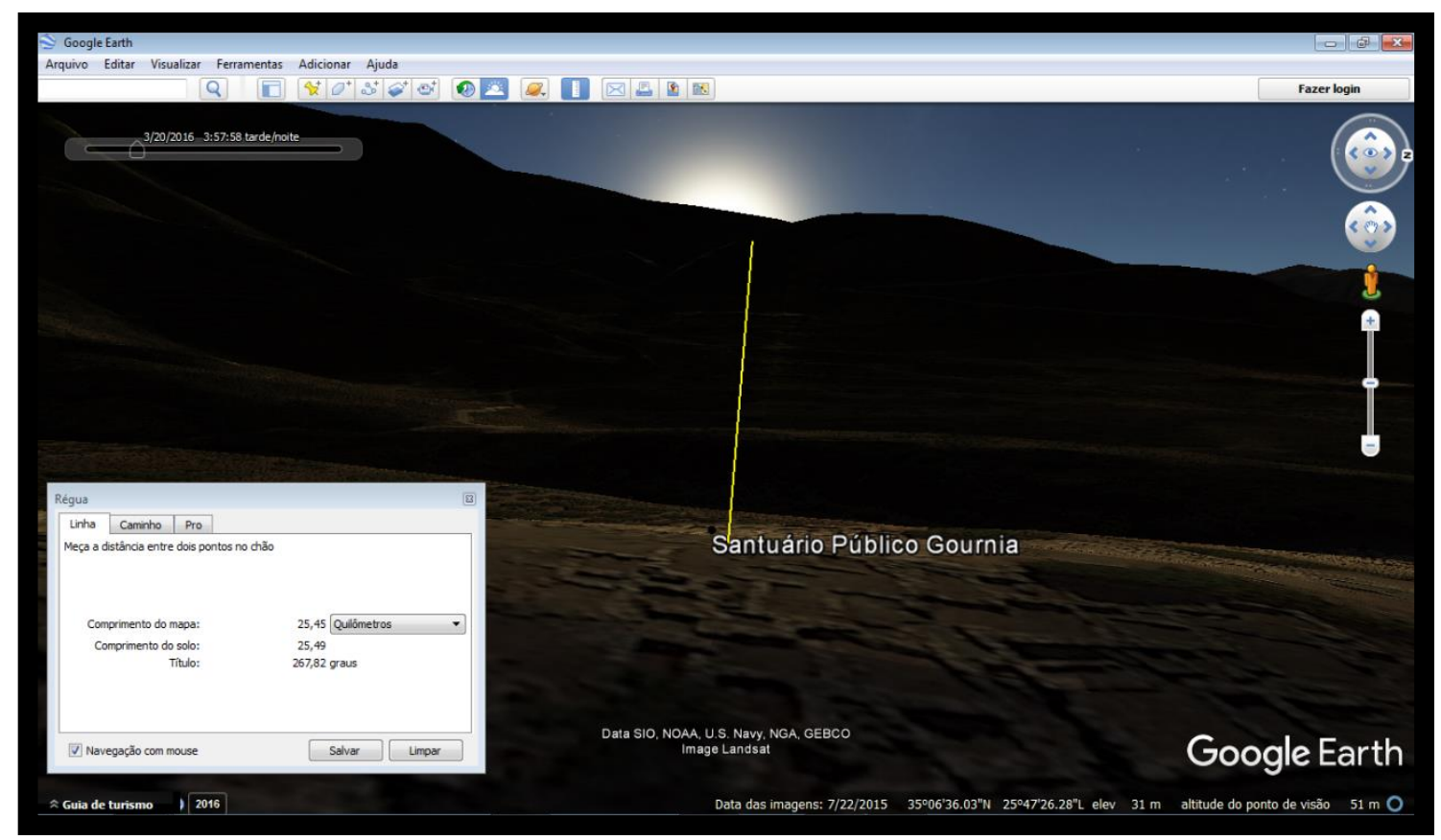

Fig. 11. Simulação 4 - Alinhamento de estrutura do santuário de Gournia em relação à montanha no percurso de equinócio de primavera de 20 de março de 2016. Gradiente $267^{\circ} 82^{\prime}$ W. Data de acesso: nov. 2016. Software: Google Earth (versão 7.1.7.2606) 


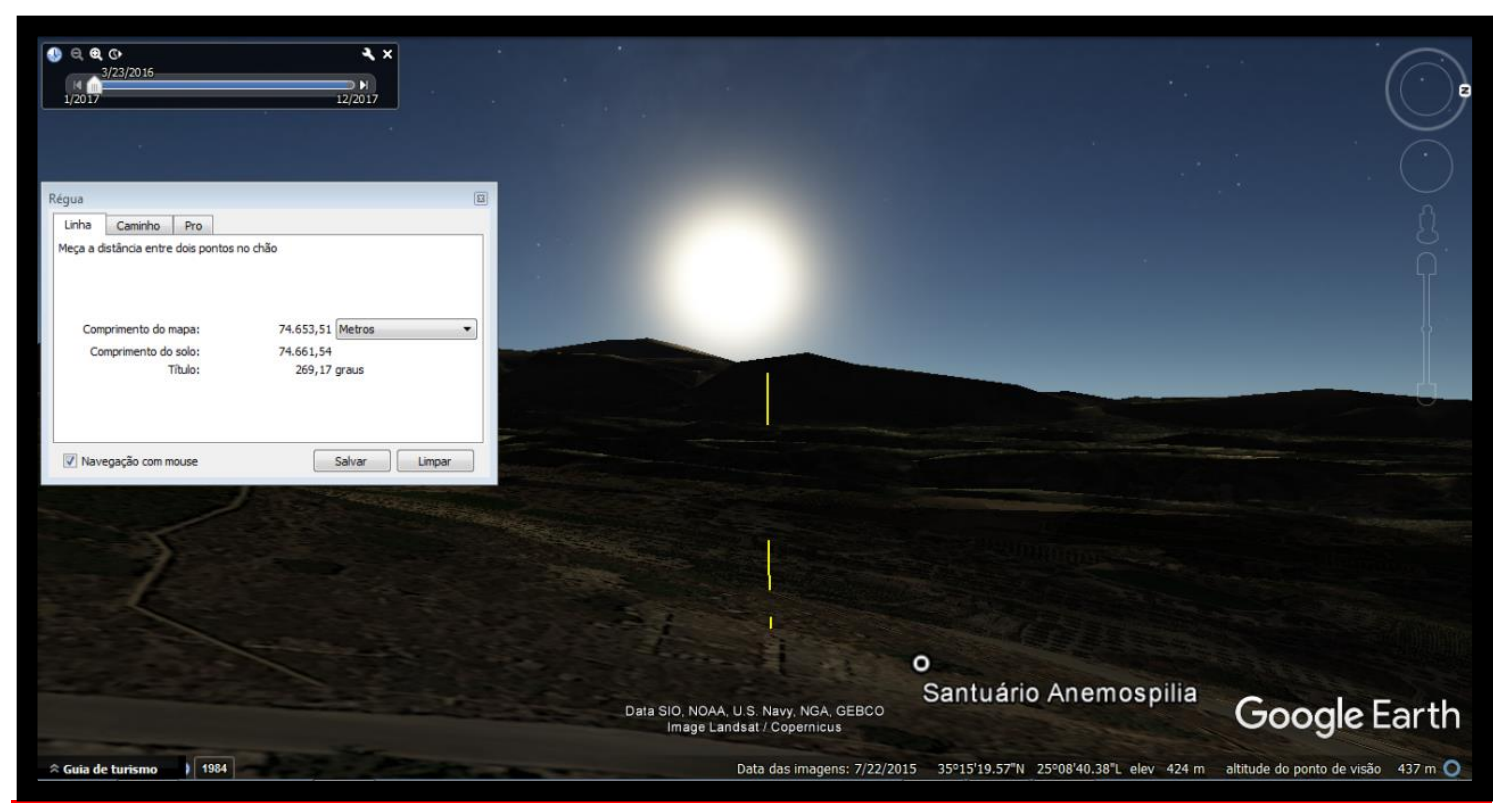

Fig.12. Simulação 5 - Alinhamento de estrutura do santuário de Anemospilia em relação à montanha no percurso de equinócio de primavera de 23 de março de 2016. Gradiente $269^{\circ} 17^{\prime}$ W. Data de acesso: nov. 2016. Software: Google Earth (versão 7.1.7.2606)

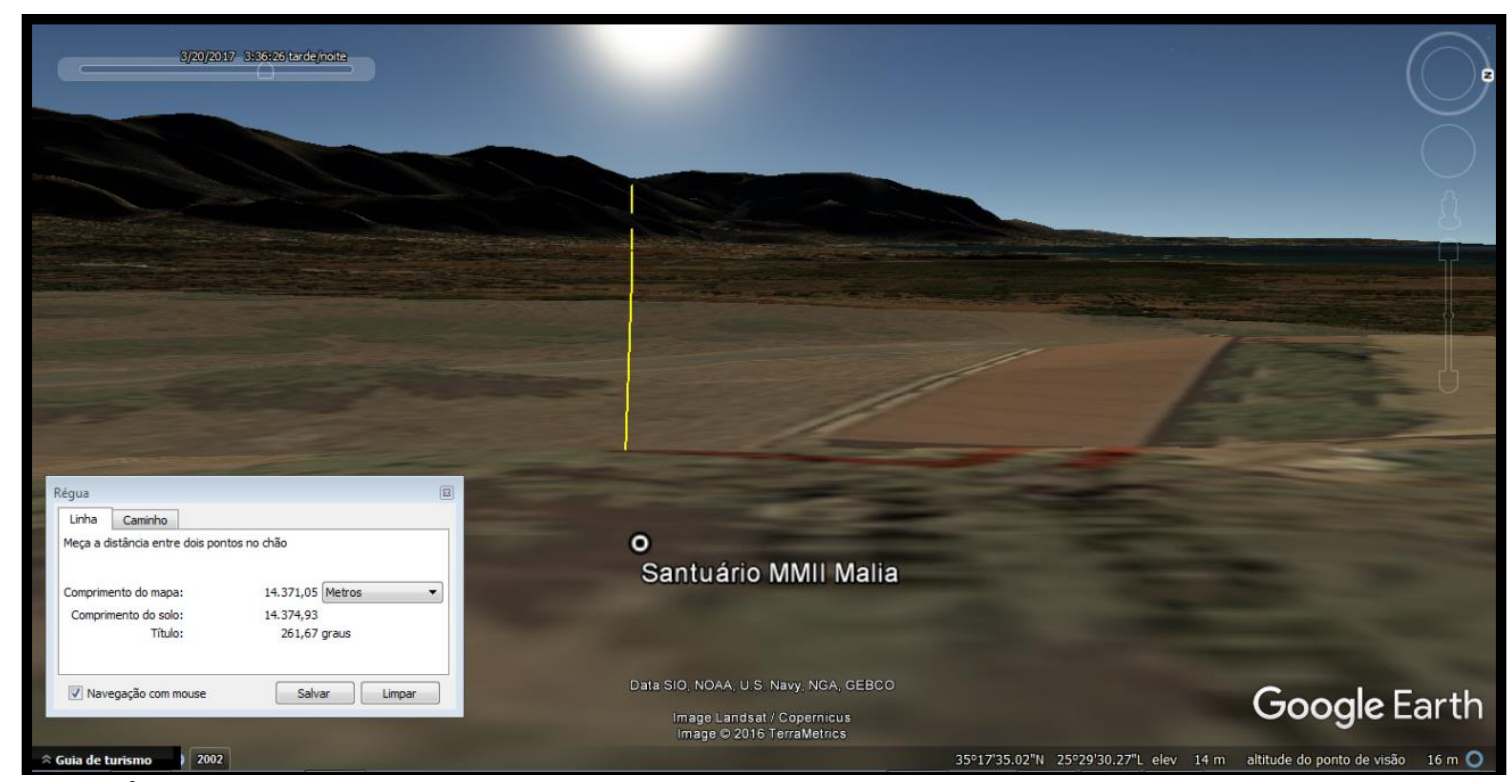

Fig. 13. Simulação 6 - Alinhamento de estrutura do santuário de Malia em relação à montanha no percurso de equinócio de primavera de 20 de março de 2017. Gradiente: $261^{\circ} 08^{\prime} W$. Data de acesso: jan. 2017. Software: Google Earth (versão 7.1.7.2606) 


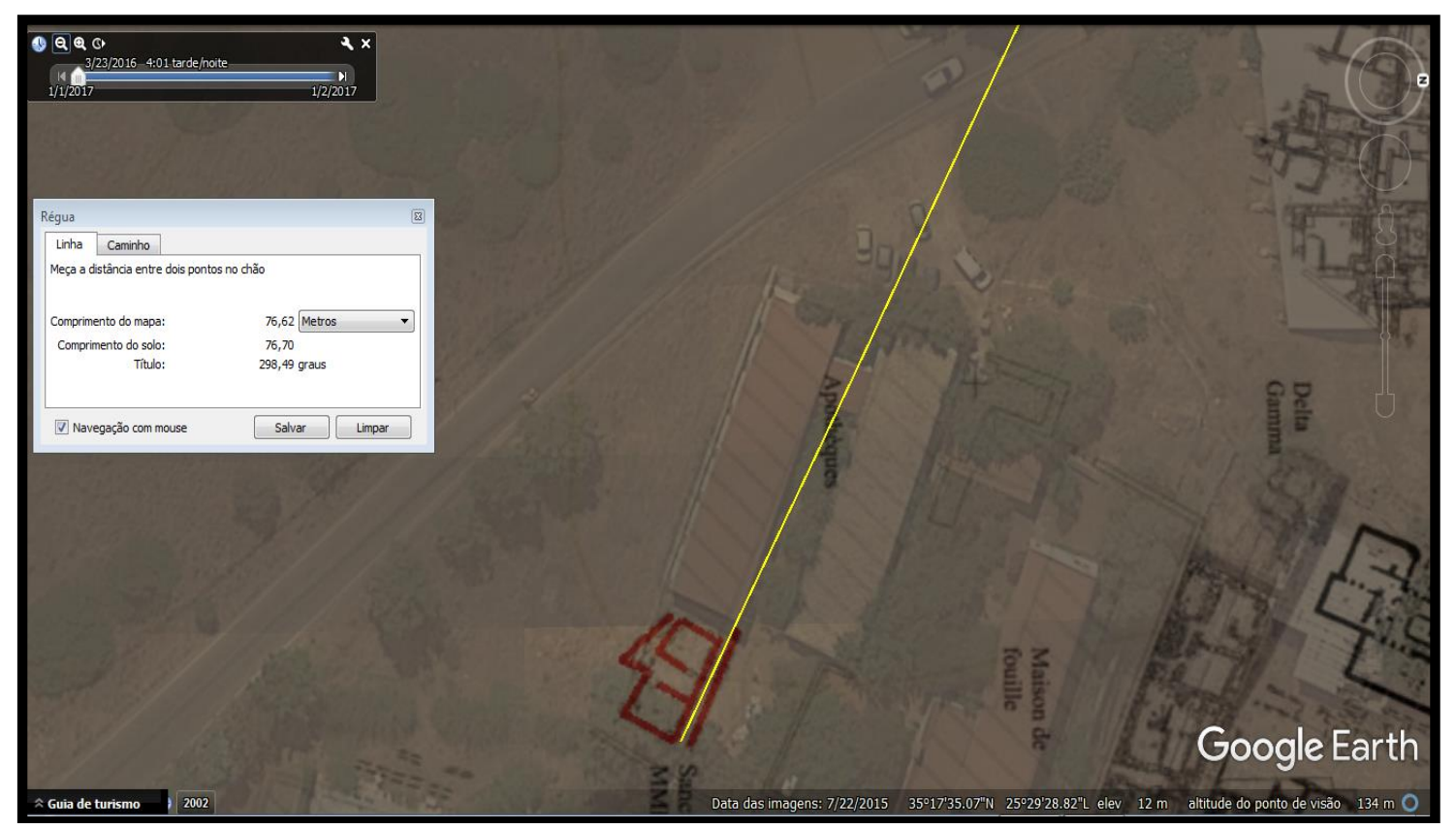

Fig. 14. Simulação 7 - Alinhamento de estrutura do santuário de Malia com sobreposição de planta topográfica ao gradiente $298^{\circ} 49^{\prime} \mathrm{NW}$. Esta posição se alinha com o solstício de verão (captura Stellarium abaixo). Data de acesso: jan. 2017. Software: Google Earth (versão 7.1.7.2606)

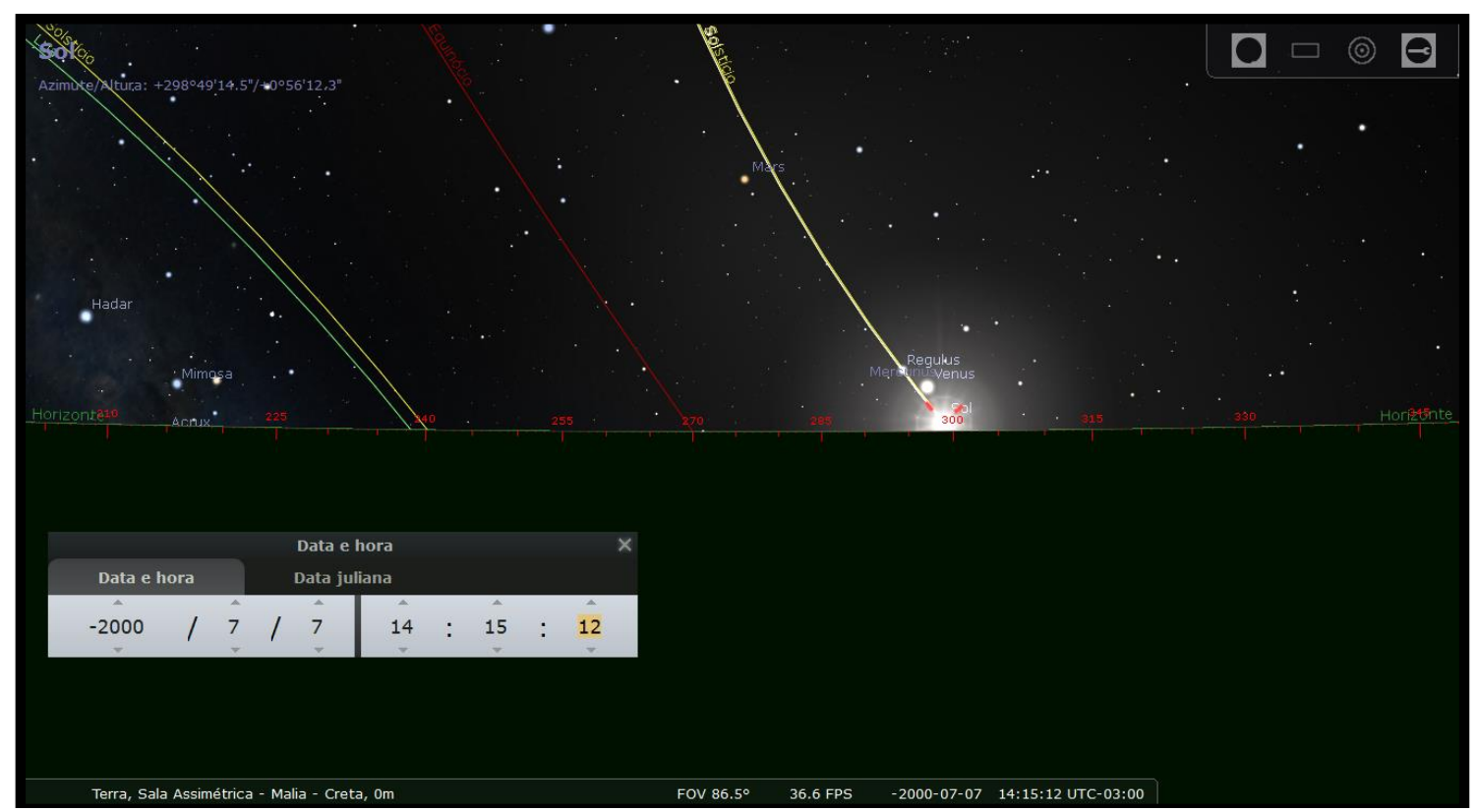

Fig. 15. Simulação 8 - Simulação Stellarium do solstício de verão. Gradiente: $298^{\circ} 49^{\prime}$ NW. Data de simulação: 07 jul. -2000 a.C. Data de acesso: 23 jan. 2017. 


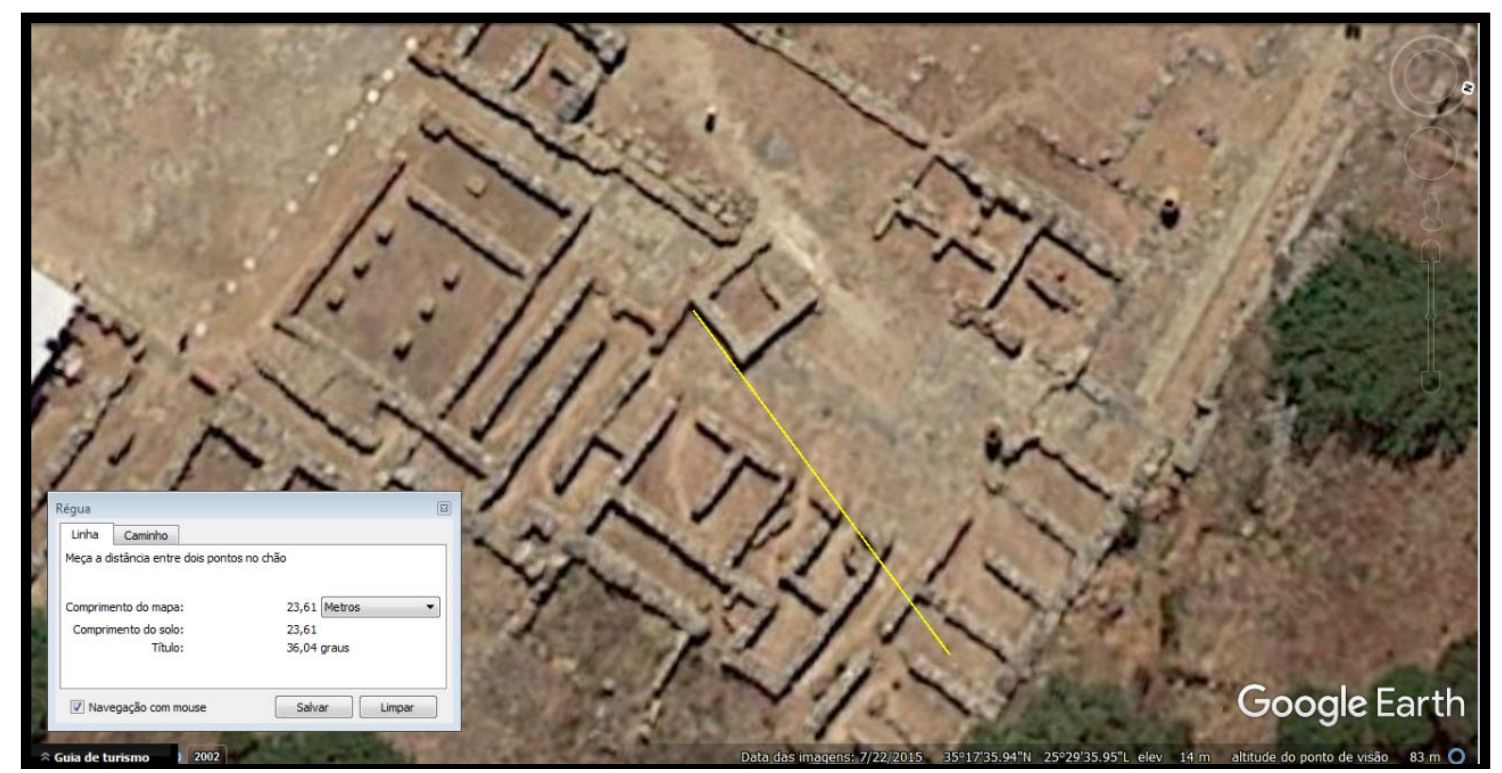

Fig. 16. Simulação 9 - Alinhamento do Edifício Oblíquo em 36,04º NE com o Helíaco de Arcturus (captura Stellarium abaixo. Data de simulação: 29 ago. -2000 a.C. Data de acesso: 10 fev. 2017.

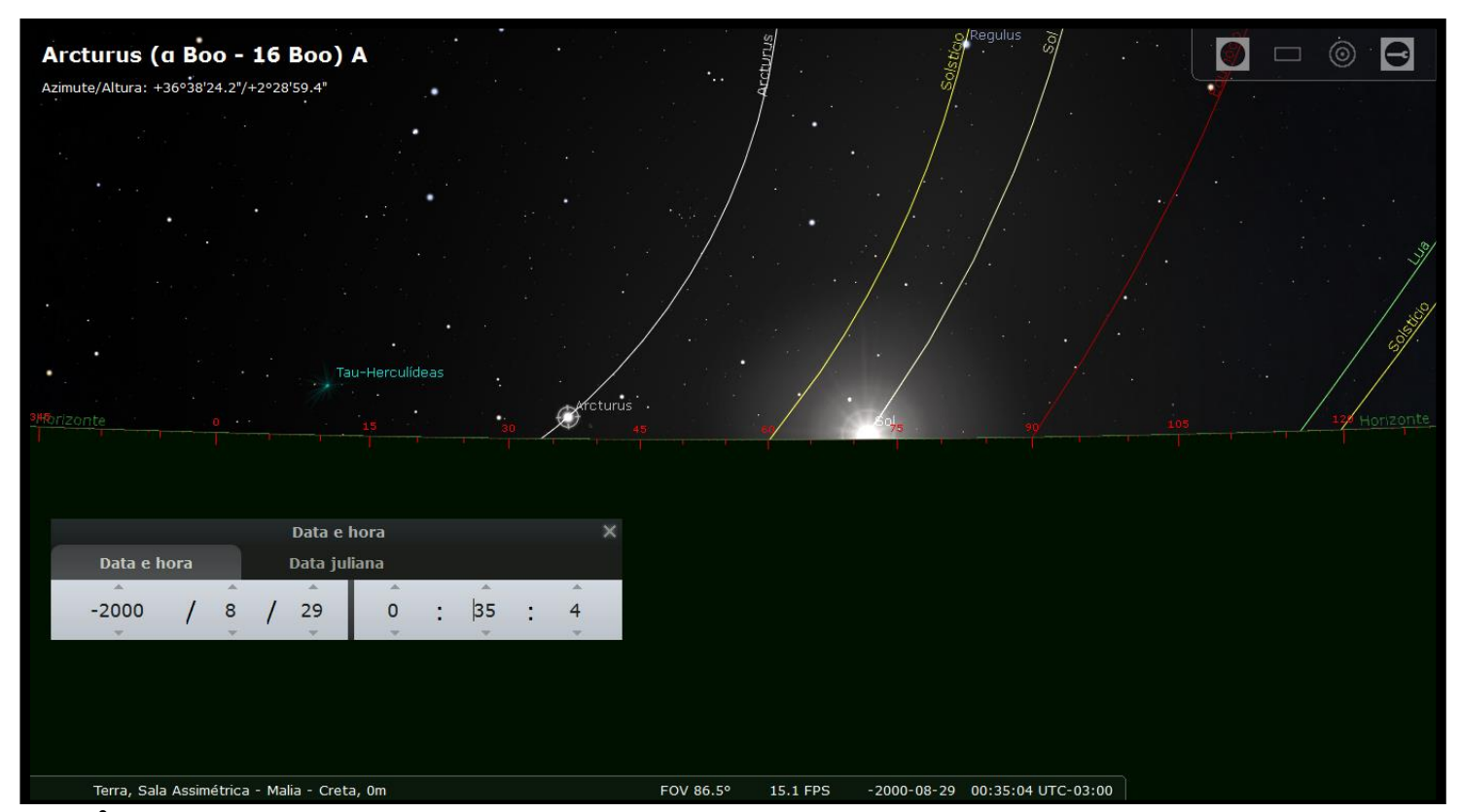

Fig. 16. Simulação 10 - Helíaco de Arcturus (círculo na estrela). Gradiente: $36,38^{\circ} \mathrm{NE}$, Assimétrica de Malia. Data de simulação: 29 ago -200o a.C. Data de acesso: 10 fev. 2017. 


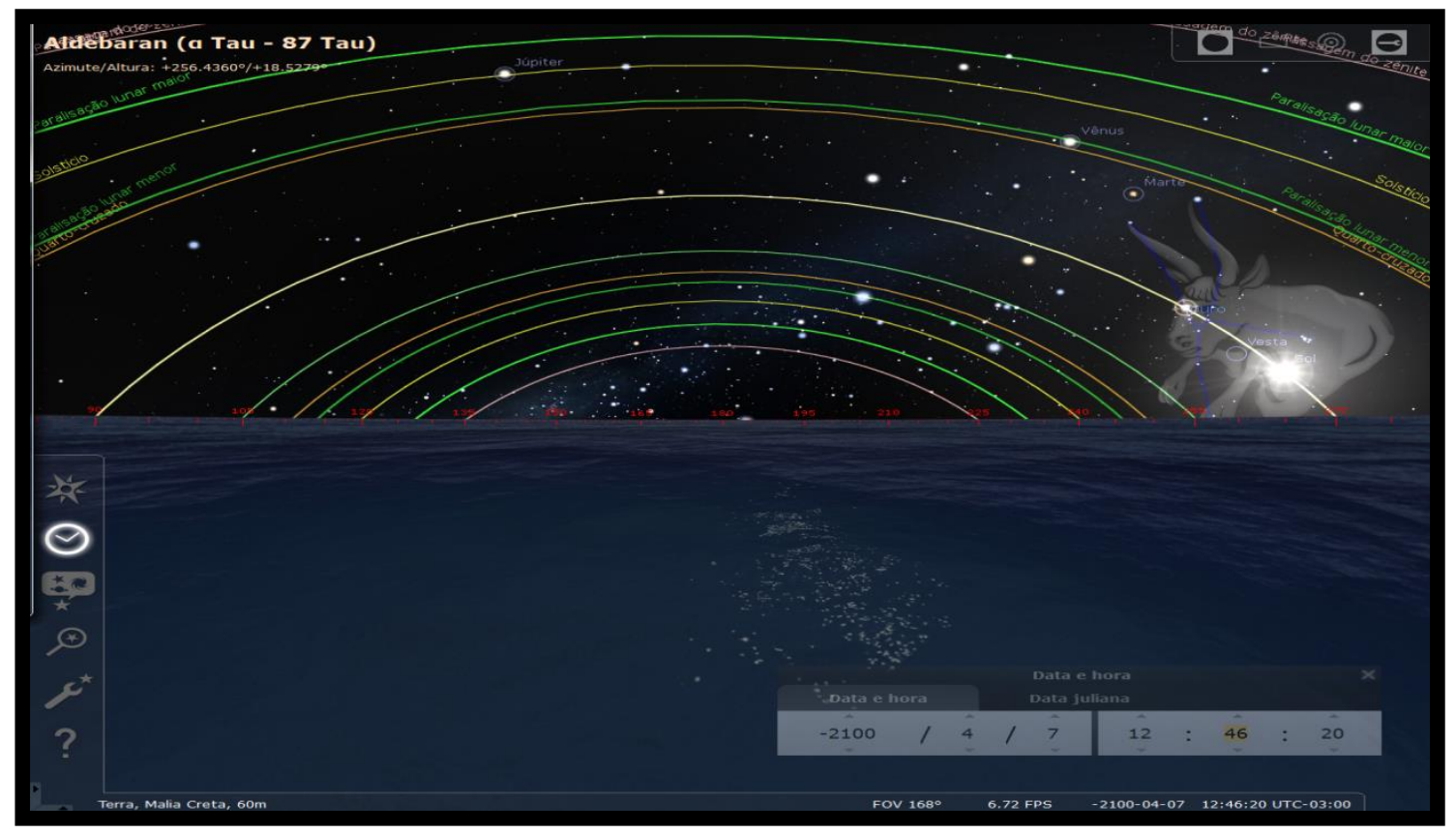

Fig. 17. Simulação 11 - Simulação Stellarium do percurso da Constelação Taurina durante o período equinocial de verão de acordo com a observação da Sala Oblíqua. Data de simulação: 07 abr. -2100 a.C. Observando as trajetórias nas arqueolinhas, podemos perceber que $\mathrm{o}$ alinhamento de Aldebaran com o gradiente da linha equinocial e o percurso na abóbada celeste do Sol na constelação são claros

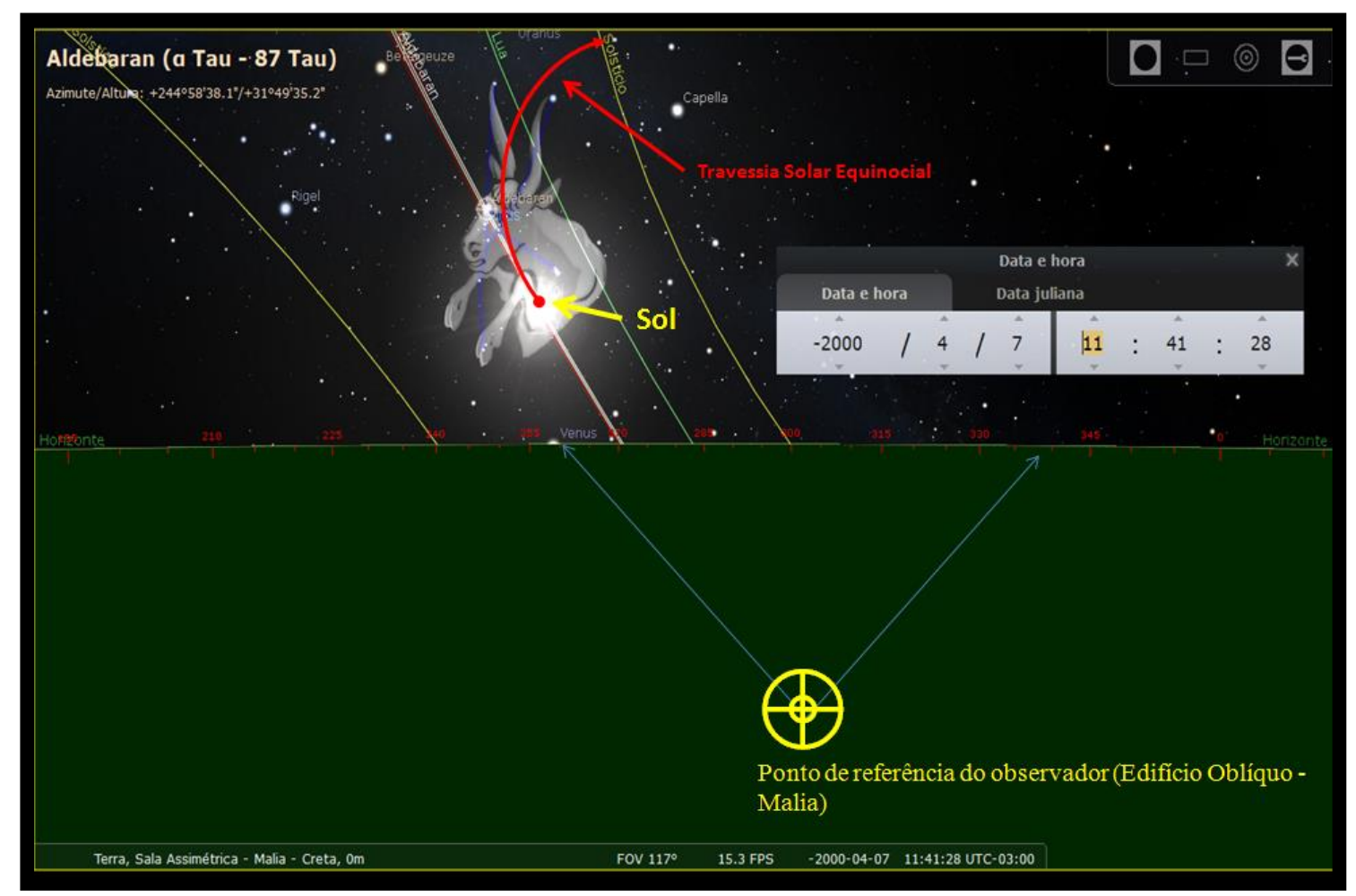

Fig. 18. Simulação 12 - Imagem pelo software Stellarium onde demonstramos o percurso observado sequencial da travessia do Sol pela constelação de Touro, iniciando no dia do equinócio da data simulada representada na imagem. A trajetória do Sol se dá durante cerca de 35 dias após a data equinocial. Durante este percurso, o Sol projeta sua sombra nas estruturas, proporcionando uma informação de tempo captada através deste sistema. Data de simulação: O7 abr. -2000 a.C. Data de acesso: 18 jan. 2017) 


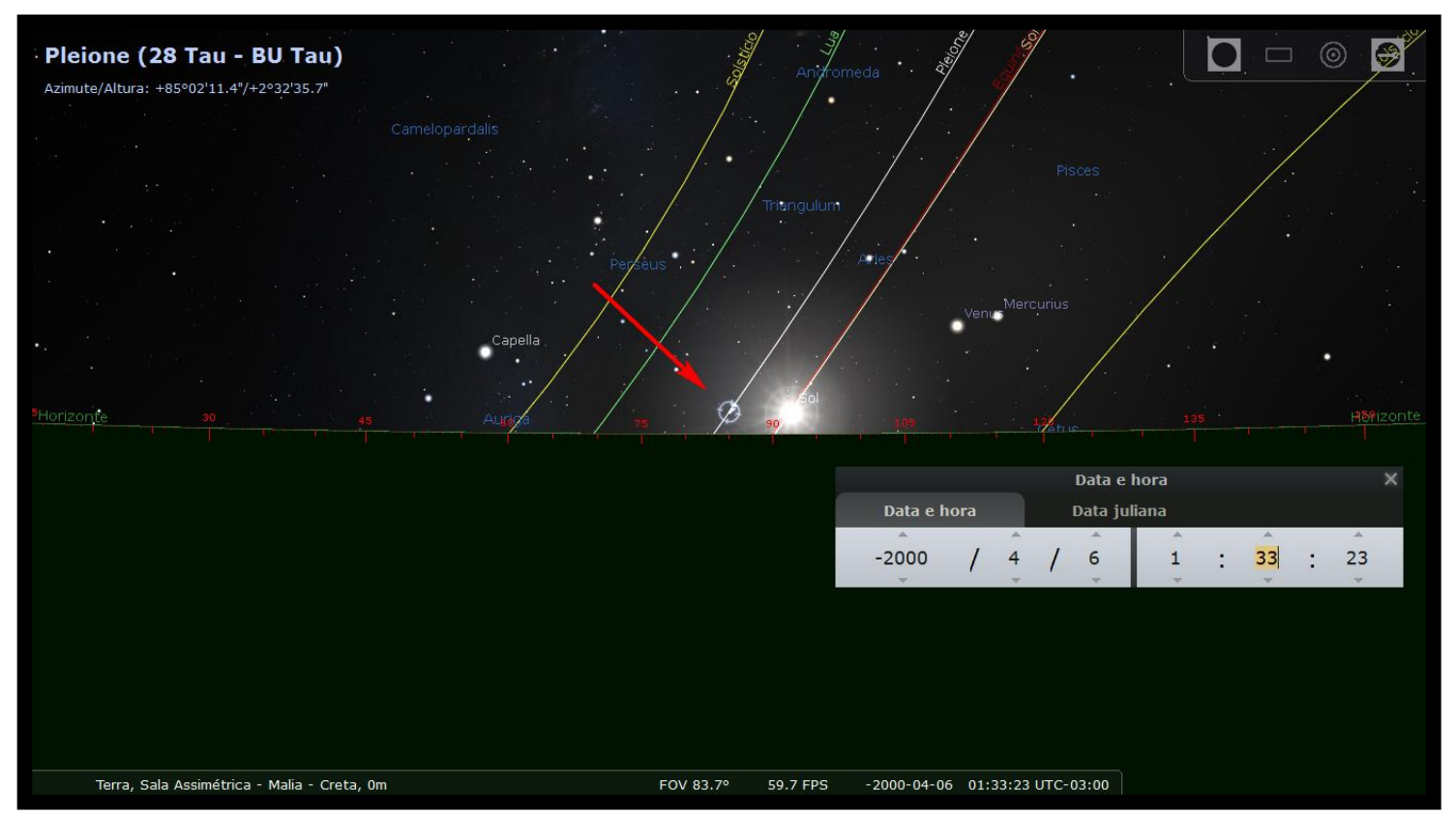

Fig. 19. Simulação 13 - Helíaco do aglomerado das Plêiades (seta vermelha, na estrela base Pleione) no equinócio de primavera, Assimétrica de Malia. Data de simulação: 06 abr. -200o a.C. Data de acesso: 23 jan. 2017.

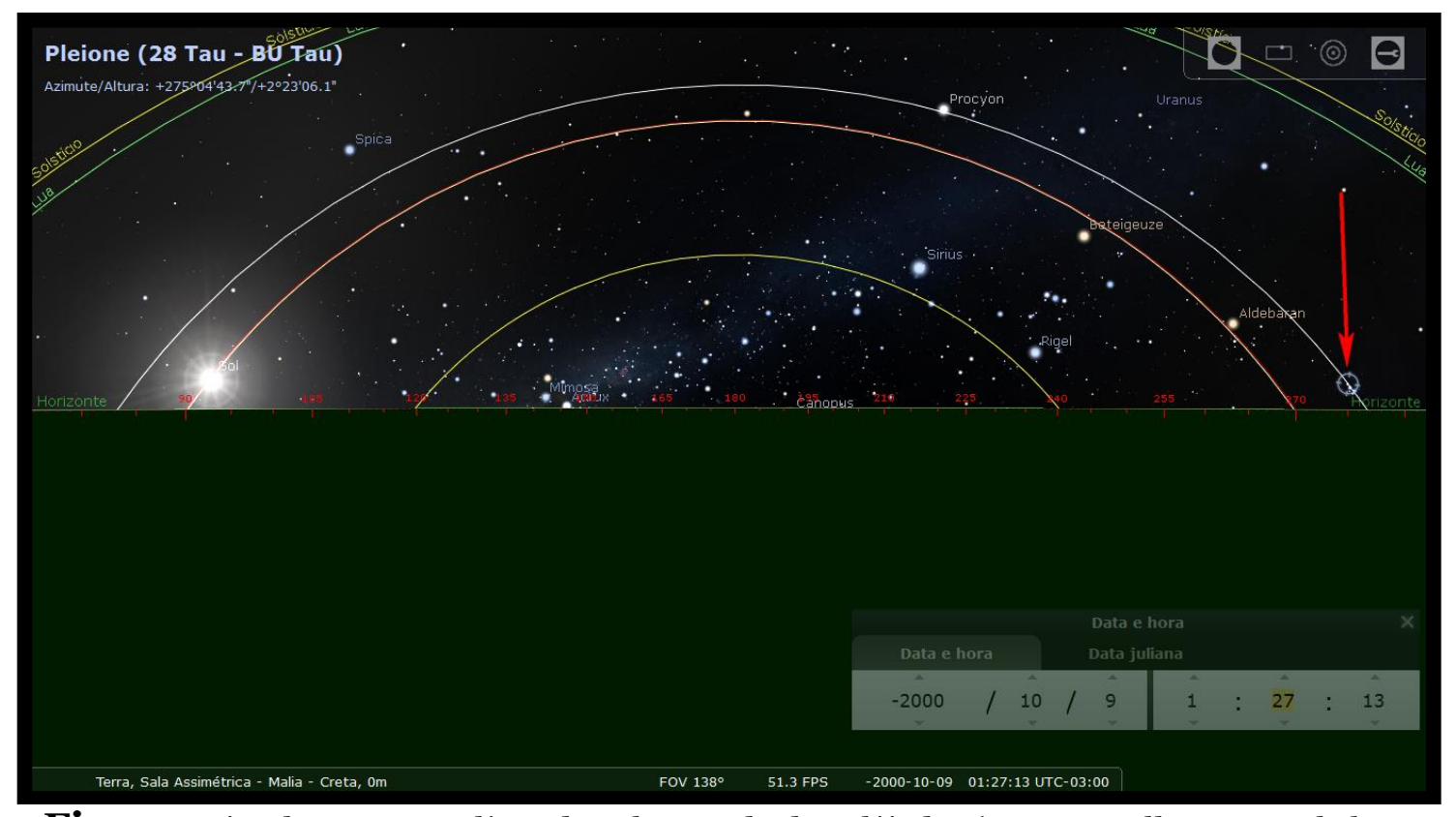

Fig. 20. Simulação 14 - Helíaco do aglomerado das Plêiades (seta vermelha na estrela base Pleione) no equinócio de outono, Assimétrica de Malia. Data de simulação: 09 out. -2000 a.C. Data de acesso: 23 jan. 2017. 


\section{REFERÊNCIAS BIBLIOGRÁFICAS}

\section{Fontes Primárias}

Heródoto. Histórias. Trad. J. Brito Broca. Rio de Janeiro: Ediouro 2001. Hesíodo. Os trabalhos e os dias. Trad. Alessandro Rolim de Moura. Curitiba: Segesta, 2012.

Homero. Ilíada. Trad. de Manuel Odorico Mendes. São Paulo: Martin Claret, 2003. Brasil, 2009. Odisséia. Trad. de Manuel Odorico Mendes. São Paulo: E-Books

\section{Bibliografia Crítica}

Adams, Ellen. Power and ritual in Neopalatial Crete: a regional comparison. World Archaeology, vol.36. Oxfordshire: Taylor \& Francis, 2004, p. 26-42.

Allegrette, Álvaro H. Organização espacial no Palácio de Malia (1700-1450 a.C.). Dissertação de mestrado. São Paulo: FFLCH/USP, 1991.

. A Cripta Hipostila: análise espacial da arquitetura minoica do Período Protopalacial (1900-1700 a.C.). Tese de doutorado. São Paulo: FFLCH/USP, 1997.

Bietak, Manfred; Nannó, Marinatos; Clairy, Palivou. Taureador scenes In Tell El-Daba (Avaris) and Cnossos. Viena: Österreichischen Akademie der Wissenschaften, 2007.

Blomberg, Mary; Göran, Henriksson. Evidence for the Minoan origins of stellar navigation in the Aegean. Actes de la Vème Conférence Annuelle de la SEAC, Gdansk: 1997.

Casson, Lionel. Los antiguos marinos. Buenos Aires: Paidós, 1967.

Chapoutier, Fernand; René, Joly. Fouilles exécutées a Mallia par l'École Française d'Athènes (1925-1926). Paris: Librarie Orientaliste Paul Geuthner, 1936.

Corvisier, Jean-Nicolas. Les grecs et la mer. Paris: Belles Lettres, 2008.

Cunha, Marcos Davi Duarte da. A Creta Minoica: O poder da talassocracia da realeza palaciana no Mar Mediterrâneo entre os séculos XVI e XV a.C.

Dissertação de mestrado. Rio de Janeiro: UERJ, 2013.

Dickinson, Oliver. The Aegean from Bronze Age to Iron Age. New York: Routledge Taylor \& Francis, 2006.

2008.

. The Aegean Bronze Age. New York: Cambridge University Press,

Effenterre, Henri van. Le palais de Mallia et la cité minoenne. Rome:

Dell'Ateneo, 1980, vol. 2. Les égéens - Aux origines de la Grèce. Paris: Armand Colin, 1986.

Evans, Arthur. Scripta Minoa: The written focuments of Minoan Crete, with special reference to the archives of Cnossos. Oxford: Clarendon Press, 1909.

Fadin, Lionel. Plan topographique de Malia. Athens: EFA, 2004. 
Faure, P. La vie quotidienne en Crète au temps de Minos (1500 av. J.-C.). Journal of Hellenic Studies, vol. 94, 1974, p. 226-227.

Hawes, Harriet Boyd. Gournia, Vasiliki, and other Prehistoric sites on the Isthmus of Hierapetra. Philadelphia: INSTAP Academic Press, 2014.

Henriksson, Goran; Blomberg, Mary. The archaeoastronomical results of three Bronze Age buildings at Agia Triada, Crete. In: Ancient cosmologies and modern prophets. Proceedings of the $20^{\text {th }}$ Conference of the European Society for Astronomy in Culture. Slovenia: EBSCO Publishing, 2013, p. 177-186.

Holgado, Carmen Poyato. Lugares de culto y cantuarios de Época Postpalacia en la Creta minoica: una revisión critica. Madrid: Universidad Autónoma de Madrid, 1989.

Hood, Sinclair. Os minoicos. Lisboa: Editorial Verbo, 1973.

Hooker, J. T. et al. Lendo o passado. São Paulo: Melhoramentos/EDUSP, 1996.

Koehl, Robert B. The sacred marriage in Minoan religion and ritual. Aegaeum, vol. 22, 2001, p. 237-243.

Lambrou-Phillipson, Connie. Seafaring in the Bronze Age Mediterranean: the parameters involved in maritime travel. Aegaeum, vol. 7, 1991, p.11-19.

Langohr, Charlotte. Perifereia, étude régionale de la Crète aux Minoen Récent II-IIIB (145O-12OO a.C.). Louvain-la-Neuve: Presses Universitaires de Louvain, 2009.

Letesson, Quentin. Du phénotype au génotype: Analyse de la syntaxe spatiale en architecture minoenne (MMIIIB - MRIB). Louvain-la-Neuve: Presses Universitaires de Louvain, 2009.

Linacero, Cristina Delgado. El toro en el Mediterraneo. Análisis de su presencia y significado em las grande culturas del mundo antiguo. Madrid: Simancas, 1996.

Libros, 2007.

. Juegos taurinos en los Albores de la Historia. Madrid: Egartorre

Lull, José. La astronomía en el Antiguo Egipto. Valencia: Publicacions de la Univesitat de Valencia, 2006.

Mcenroe, John C. Architecture of Minoan Crete. Constructing identity in the Aegean Bronze Age. Austin: University Texas Press, 2010.

Marinatos, Nanno. Minoan sacrificial ritual. Cult, pratice, and symbolism. Stockholm: Paul Áströms förlag, 1986.

Minoan religion. Ritual, image and symbol. Columbia: University of South Carolina Press, 1993.

Minoan kingship and the solar goddess. A Near Eastern koine.

Illinois: University of Illinois Press, 2010.

Mourão, Ronaldo Rogério de Freitas. Dicionário Enciclopédico de Astronomia e Astronáutica. Rio de Janeiro: Nova Fronteira, 1995.

Pelon, Olivier; Andersen, Elga; Olivier, Jean-Pierre. Le palais de Malia V.

Études Crétoises XXV, vol. II. Paris: Librarie Orientaliste Paul Geuthner, 1980.

$185-197$.

Les deux destructions du palais de Malia. Aegaeum, vol. 26, 2005, p. 
Platon, Nicolas. La Civilisation Egéenne, du Néolithique au Bronze Récent. Paris: Éditions Albin Michel, 1981.

Polcaro, Andrea; Polcaro, Vito F. Man and sky: problems and methods of Archaeoastronomy. Firenze: Edizioni All'Insegna del Giglio para Archeologia e Calcolatori Journal n. XX, Istituto di Studi sul Mediterraneo Antico, 2009.

Pottier, Edmond. Gournia, Vasiliki and other prehistoric sites on the Isthmus of Hierapetra (Crete). Excavations of the Wells-Houston-Cramp Expeditions, 1901, 1903, 1904 by Harriet Boyd-Hawes, Blanche F. Williams, Richard B. Slager, Edith H. Hall. Journal des savants, vol. 8, 1910, p. 145-155.

Poursat, Jean-Claude. Un sanctuaire du Minoen Moyen II à Malia. Bulletin de Correspondance Hellénique, vol. 90/2, 1966, p. 514-551.

Preston, Laura Julia. A mortuary approach to cultural interaction and political dynamics on Late Minoan II-IIIB Crete, vol. I. Londres: Institute of Archaeology University College London, 2000.

Ridderstad, Marianna. Evidence of Minoan astronomy and calendrical practices. History of Astronomy Discussion Group of the West Virginia (histrol@listserv.wvu.edu). Helsinki University Observatory. Helsinki, 2009.

Rutkowski, Bogdan. The cult places of the Aegean. Avon: Yale University Press, 1986.

Shaw, Joseph. Elite Minoan architecture. Its development at Cnossos, Phaistos, and Malia. Philadelphia: INSTAP Academic Press, 2015.

Sparavigna, Amelia. Amelia. The Pleiades: the celestial herd of ancient timekeepers; Ithaca: Cornell University Press, 2008.

Thiel, Rudolf. E a Luz se fez. São Paulo: Melhoramentos, 1972.

Verderame, Lorenzo. Pleiades in Ancient Mesopotamia. Conference Astronomy in Past and Present Cultures, Société Européenne pour l'Astronomie dans la Culture (SEAC 2015), vol. 16, 2015, p. 109-117.

Watrous, Vance L. Some observations on Minoan peak sanctuaries. Liège: Aegaeum, vol. 12, 1995. p. 393-405. 